\title{
Body surface area-based versus concentration-based intraperitoneal perioperative chemotherapy in a rat model of colorectal peritoneal surface malignancy: pharmacologic guidance towards standardization
}

\author{
Lieselotte Lemoine ${ }^{1,2}$, Elsy Thijssen ${ }^{3}$, Robert Carleer ${ }^{3}$, Jirka Cops ${ }^{1,4}$, Veerle \\ Lemmens ${ }^{5}$, Peter Van Eyken ${ }^{6}$, Paul Sugarbaker ${ }^{7}$ and Kurt Van der Speeten ${ }^{1,2}$ \\ ${ }^{1}$ Department of Medicine and Life Sciences, Hasselt University, Hasselt, Belgium \\ ${ }^{2}$ Department of Surgical Oncology, Ziekenhuis Oost-Limburg, Genk, Belgium \\ ${ }^{3}$ Department of Applied and Analytical Chemistry, Institute for Materials Research (IMO), Hasselt University, Diepenbeek, \\ Belgium \\ ${ }^{4}$ Department of Medicine and Life Sciences, Biomedical Research Institute, Rehabilitation Research Center, Hasselt University, \\ Hasselt, Belgium \\ ${ }^{5}$ Department of Medicine and Life Sciences, Dynamic Bioimaging Laboratory, Advanced Optical Microscopy Centre, Biomedical \\ Research Institute (BIOMED), Hasselt University, Hasselt, Belgium \\ ${ }^{6}$ Department of Pathology, Ziekenhuis Oost-Limburg, Genk, Belgium \\ ${ }^{7}$ Center for Gastrointestinal Malignancies, MedStar Washington Hospital Center, Washington, DC, USA \\ Correspondence to: Lieselotte Lemoine, email: lieselotte.lemoine@uhasselt.be \\ Keywords: peritoneal surface malignancy; colorectal cancer; HIPEC; oxaliplatin; dosimetry \\ Received: November 24, $2018 \quad$ Accepted: January 28, $2019 \quad$ Published: February 15, 2019 \\ Copyright: Lemoine et al. This is an open-access article distributed under the terms of the Creative Commons Attribution License \\ 3.0 (CC BY 3.0), which permits unrestricted use, distribution, and reproduction in any medium, provided the original author and \\ source are credited.
}

\section{ABSTRACT}

Worldwide, cytoreductive surgery (CRS) and hyperthermic intraperitoneal perioperative chemotherapy (HIPEC) are used in current clinical practice for colorectal peritoneal surface malignancy (PSM) treatment. Although, there is an acknowledged standardization regarding the CRS, we are still lacking a much-needed standardization amongst the various intraperitoneal (IP) chemotherapy protocols, including the HIPEC dosing regimen. We should rely on pharmacologic evidence building towards such a standardization. The current IP chemotherapy dosing regimens can be divided into body surface area (BSA)-based and concentrationbased protocols. A preclinical animal study was designed to evaluate pharmacologic advantage (PA), efficacy and survival. WAG/Rij rats were IP injected with the rat colonic carcinoma cell line CC-531. Animals were randomized into three groups: CRS alone or CRS combined with oxaliplatin-based HIPEC (either BSA- or concentrationbased). There was no difference in PA between the two groups $(p=0.283)$. Platinum concentration in the tumor nodule was significantly higher in the concentrationbased group $(p<0.001)$. Median survival did not differ between the treatment groups $(p<0.250)$. This preclinical study, in contrast to previous thinking, clearly demonstrates that the PA does not provide any information about the true efficacy of the drug and emphasizes the importance of the tumor nodule as pharmacologic endpoint. 


\section{INTRODUCTION}

Worldwide, cytoreductive surgery (CRS) and hyperthermic intraperitoneal perioperative chemotherapy (HIPEC) are used in current clinical practice for selected patients diagnosed with peritoneal surface malignancy (PSM) of colorectal origin $[1,2]$. This combined treatment modality has resulted in significant survival benefit, with a median overall survival of 41.7 months (results presented at the ASCO annual meeting in Chicago) [3]. Clearly defined standardization of CRS, based on the work of Sugarbaker et al. [4, 5], has resulted in high-quality reproducible surgery performed at expert centers worldwide. In contrast, there is still a large variety of HIPEC treatment modalities used in current clinical practice. Methodological variations to be considered are: technique (open versus closed), normothermic versus hyperthermic chemotherapy, drug selection, drug dose, exposure time and dosing regimen $[1,6]$. Conceptually, to standardize HIPEC, a randomized trial would be required with each variable as the only discriminating factor, but it is clear that multiple well-designed randomized controlled trials will not be conducted. Rather, we should rely on validated analytical assays and well-designed preclinical studies to build pharmacologic data towards improved and standardized HIPEC regimens. Therefore, an experimental study was performed to pharmacologically evaluate toxicity, efficacy and survival of body surface area (BSA)-based and concentration-based intraperitoneal (IP) chemotherapy in a rat model of colorectal PSM.

Most groups use a drug dose based on calculated BSA $\left(\mathrm{mg} / \mathrm{m}^{2}\right)$ in analogy to systemic chemotherapy regimens. These regimens take BSA as a measure for the effective peritoneal contact area; the peritoneal surface area in the Dedrick formula [7]. The Dedrick formula describes; rate of mass transfer $=\mathrm{PA}\left(\mathrm{C}_{\mathrm{Per}}-\mathrm{C}_{\mathrm{BI}}\right)$; where: $\mathrm{PA}=$ permeability area $(\mathrm{PA}=$ effective peritoneal contact area A x permeability $\mathrm{P}), \mathrm{C}_{\mathrm{Per}}=$ concentration in peritoneal cavity and, $\mathrm{C}_{\mathrm{BI}}=$ concentration in the blood [8]. Rubin et al. however, demonstrated there is an imperfect correlation between actual peritoneal surface area and calculated BSA $[9,10]$. There may also be sex differences in peritoneal surface areas, which in turn affects absorption characteristics [11]. As a result, BSA-based IP chemotherapy will deliver a fixed dose (BSA-based) diluted in varying volumes of perfusate; i.e.; different concentrations depending on substantial differences in the body composition of patients and differences in the HIPEC technique (open versus closed abdomen). This implicates a high predictability of systemic chemotherapy levels and thus toxicity but a low predictability of peritoneal levels and thus tumor exposure to the drug. From the Dedrick formula we know that peritoneal concentration and not peritoneal dose is the driving diffusion force [7]. In that context, concentration-based chemotherapy offers a more predictable exposure of the tumor nodules to the IP chemotherapy and thus efficacy [12]. Unfortunately, the prize to be paid for a better prediction of the efficacy of the IP chemotherapy is a higher unpredictability of the systemic toxicity.

The aim of this manuscript is to pharmacologically evaluate toxicity, efficacy and survival of BSA-based and concentration-based IP chemotherapy in a rat model of colorectal PSM.

\section{RESULTS}

\section{Oxaliplatin in vitro cytotoxicity}

Viability of the CC-531 cell line after oxaliplatin treatment was evaluated in vitro by the 3-[4,5-dimethylthiazol-2-yl]-2,5-diphenyltetrazolium bromide (MTT) assay. Cell viability after exposure to increasing concentrations of oxaliplatin is presented in Figure 1. After treating the cells with the highest oxaliplatin dose, $75 \mu \mathrm{g} / \mathrm{mL}\left(150 \mathrm{mg} / \mathrm{m}^{2}\right.$ in $\left.2 \mathrm{~L} / \mathrm{m}^{2}\right), 53.6$ $\pm 2.1 \%$ of the cells were still alive when compared to the control group.

\section{Maximum tolerated dose}

To determine in vivo toxicity of the CC-531 cell line, rats were treated with CRS and HIPEC with increasing doses of oxaliplatin $\left(40-150 \mathrm{mg} / \mathrm{m}^{2}\right.$ in $2 \mathrm{~L} /$ $\mathrm{m}^{2}$ ). At laparotomy, all animals had macroscopic tumor deposits. The injection site, greater omentum, liver hilum, perisplenic area and mesentery were identified as the most affected sites (Figure 2). Overall median modified peritoneal cancer index (PCI) before CRS was similar in all groups $(p=0.089): 40 \mathrm{mg} / \mathrm{m}^{2}: 13.0$ $(11.5-13.0) ; 60 \mathrm{mg} / \mathrm{m}^{2}: 5.0(5.0-6.5) ; 100 \mathrm{mg} / \mathrm{m}^{2}: 6.0$ $(6.0-8.5) ; 150 \mathrm{mg} / \mathrm{m}^{2}: 7.0(6.5-7.0)$. R2a resection was achieved in all animals, leaving residual tumor deposits smaller than $2.5 \mathrm{~mm}$ on the bowel surface. Intraabdominal temperature at the outflow drain and rectal temperature were constant and similar in both subgroups, with a median temperature of $40.3^{\circ} \mathrm{C}(39.7-40.7)(p=$ $0.224)$ and $36.3^{\circ} \mathrm{C}(35.6-37.3)(p=0.862)$, respectively. Figure 3 demonstrates the evolution of mean body weight in the four subgroups, 14 days postoperatively. The lowest mean body weight was recorded on the 5 th postoperative day: reduction of $10.6 \pm 0.8 \%(40 \mathrm{mg} /$ $\left.\mathrm{m}^{2}\right), 16.2 \pm 3.1 \%\left(60 \mathrm{mg} / \mathrm{m}^{2}\right), 19.0 \pm 0.8 \%\left(100 \mathrm{mg} / \mathrm{m}^{2}\right)$ and $17.1 \pm 0.3 \%\left(150 \mathrm{mg} / \mathrm{m}^{2}\right)$. All animals generally gained weight from the 6th postoperative day onwards. Besides weight loss, commonly observed side effects were reduced activity and less grooming. All animals survived the 14-day period and were euthanized. Autopsy was performed in all but two rats, treated with CRS and 
$40 \mathrm{mg} / \mathrm{m}^{2}$ oxaliplatin-based HIPEC. PCI score at autopsy did not differ between the groups $(p=0.141): 7.0(40 \mathrm{mg} /$ $\left.\mathrm{m}^{2}\right), 5.0(4.0-6.0)\left(60 \mathrm{mg} / \mathrm{m}^{2}\right), 5.0(3.5-5)(100 \mathrm{mg} /$ $\left.\mathrm{m}^{2}\right)$ and $1.0(0.5-2.5)\left(150 \mathrm{mg} / \mathrm{m}^{2}\right)$. Maximum tolerated dose (MTD) was defined at $150 \mathrm{mg} / \mathrm{m}^{2}$ oxaliplatin in 2 $\mathrm{L} / \mathrm{m}^{2} 0.9 \%(\mathrm{w} / \mathrm{v}) \mathrm{NaCl}$ carrier solution.

\section{Body surface area-based versus concentration- based HIPEC}

\section{Cytoreductive surgery}

At laparotomy, all animals had macroscopic tumor deposits with the greater omentum, liver hilum, perisplenic area, mesentery, bowel surface and gonadal fat pads identified as the most affected sites (Table 1). Overall mean modified PCI before CRS was significantly different between the HIPEC-CONC group, the CRS group ( $p<$ $0.001)$ and the HIPEC-BSA group $(p=0.029)$ : CRS group: $8.1 \pm 2.4$; HIPEC-BSA: $9.7 \pm 2.3$; HIPEC-CONC: $11.5 \pm 2.0$. Completeness of resection, denoted by the $\mathrm{R}$-score, did not differ between the groups $(p=0.543)$. As no bowel resections were performed and no anastomosis were made, a R1 resection could not be achieved (Table 1). $\mathrm{R} 2 \mathrm{a}$ resection was accomplished in 45 rats and a $\mathrm{R} 2 \mathrm{~b}$ resection was accomplished in 18 rats. Median duration of surgery was $39(35-43)$ minutes.

\section{Hyperthermic intraperitoneal perioperative chemotherapy}

During HIPEC, intra-abdominal temperature at the outflow drain and rectal temperature were constant and similar in all subgroups, with a mean intra-abdominal temperature of $40.2 \pm 0.7^{\circ} \mathrm{C}(p=0.276)$ and a mean rectal temperature of $35.9 \pm 0.7^{\circ} \mathrm{C}(p=0.434)$ (Figure 4). Mean duration of anesthesia was 114.1 \pm 11.4 minutes.

\section{Pharmacology of oxaliplatin during HIPEC}

Oxaliplatin-derived platinum $(\mathrm{Pt})$ concentrations in plasma and peritoneal fluid, of rats treated with either concentration- or BSA-based HIPEC, are depicted in Figure 5. Area-under-the curve (AUC) of the plasma and peritoneal fluid compartment, reflecting toxicity and efficacy of the treatment, was significantly different between the treatment groups $(p<0.001)$. The ratio of AUC peritoneal fluid over AUC plasma, the pharmacologic advantage (PA), was similar in both groups $(p=0.283)$ with a median PA of 19.60 (16.02-25.82). $\mathrm{Pt}$ concentration in the tumor nodule was significantly higher in the HIPEC-CONC group; $20.44 \pm 9.10 \mathrm{ng} / \mathrm{mg}$, as compared to the HIPEC-BSA group; $4.74 \pm 2.49 \mathrm{ng} /$ $\operatorname{mg}(p<0.001)$.

\section{Apoptosis measurements}

Apoptosis in the center and outer layer of the tumor nodule was evaluated in the HIPEC-CONC $(n=10)$ and the HIPEC-BSA $(n=10)$ group by means of immunohistochemistry (IHC) staining for activated caspase-3 (Figure 6). Median number of cells $/ \mathrm{mm}^{2}$ was $25.56(13.16-46.5)$ in the center and $31.70(9.47$ $-73.73)$ in the outer layer of the tumor nodule in the HIPEC-CONC group (Figure 7). In the HIPEC-BSA group, median number of cells $/ \mathrm{mm}^{2}$ was 66.84 (1.67-
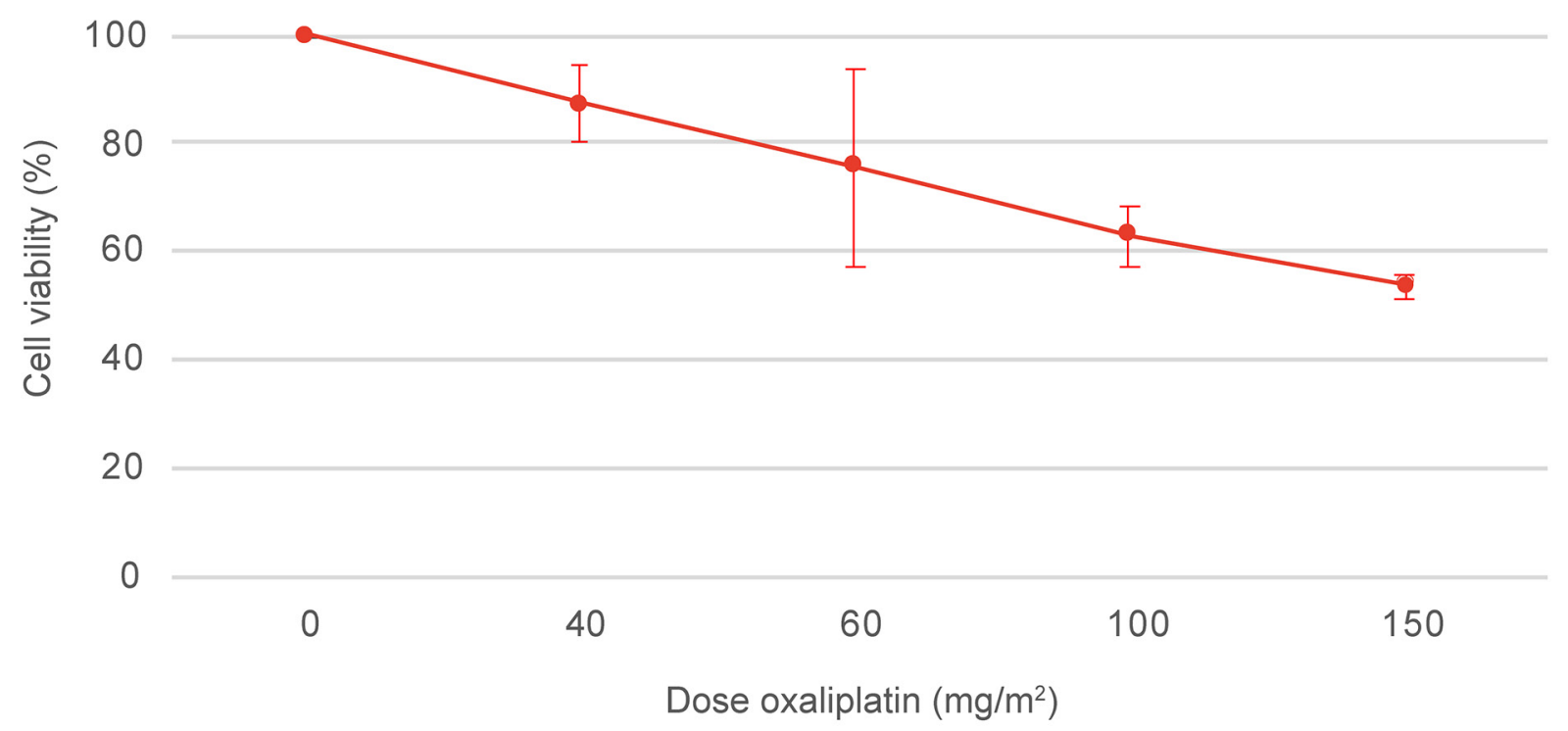

Figure 1: MTT assay of the CC-531 cell line after oxaliplatin treatment. Cell viability was assessed after exposure to increasing concentrations of oxaliplatin, $0,40,60,100$ and $150 \mathrm{mg} / \mathrm{m}^{2}$ in $2 \mathrm{~L} / \mathrm{m}^{2}$. Values are mean $\pm \mathrm{SD}(\mathrm{n}=3)$. 
194.29) in the center of the tumor nodule and 131.06 $(10.67-357.62)$ in the outer layer of the nodule (Figure 7). There was no significant difference in amount of apoptosis, both in the center $(p=0.279)$ and outer layer ( $p=0.388)$ of the tumor nodule, between the HIPEC treatment groups. Furthermore, within each treatment group, there was no difference between amount of apoptosis in the center and outer layer of the nodule, nor could a correlation between Pt concentration in the nodule at the end of HIPEC and amount of apoptosis be found.

\section{Survival}

The lowest mean body weight was recorded on the 5th (CRS and HIPEC-CONC) or 7th (HIPEC-BSA) postoperative day (Figure 8). Weight reduction was significantly lower in the CRS group, $11.8 \pm 0.4 \%$ when compared to the HIPEC-CONC group, $19.1 \pm 0.9 \%(p$ $<0.001)$ and the HIPEC-BSA group, $19.5 \pm 1.9 \%(p=$ 0.003). Besides weight loss, commonly observed side effects were reduced activity and less grooming.

Survival curves are depicted in Figure 9. Median survival was 38 (95\% confidence interval (c.i.) 26 to 50) days in the CRS group, 9 (95\% c.i. 6 to 12) days in the HIPEC-BSA group, 24 (95\% c.i. 0 to 51) days in the HIPEC-CONC group; and did not differ between the groups $(p=0.250)$. After 140 days, 9 rats were still alive: 2 in CRS group, 2 in HIPEC-BSA group and 5 in HIPEC-CONC group. At autopsy, 4 of these 9 rats presented only with a very small nodule on the bowel surface: 1 in CRS group, 1 in HIPEC-BSA group, and 2 in HIPEC-CONC group. All rats in the CRS group survived the surgery, whereas 4 rats in the HIPECCONC group did not wake up from the anesthesia.
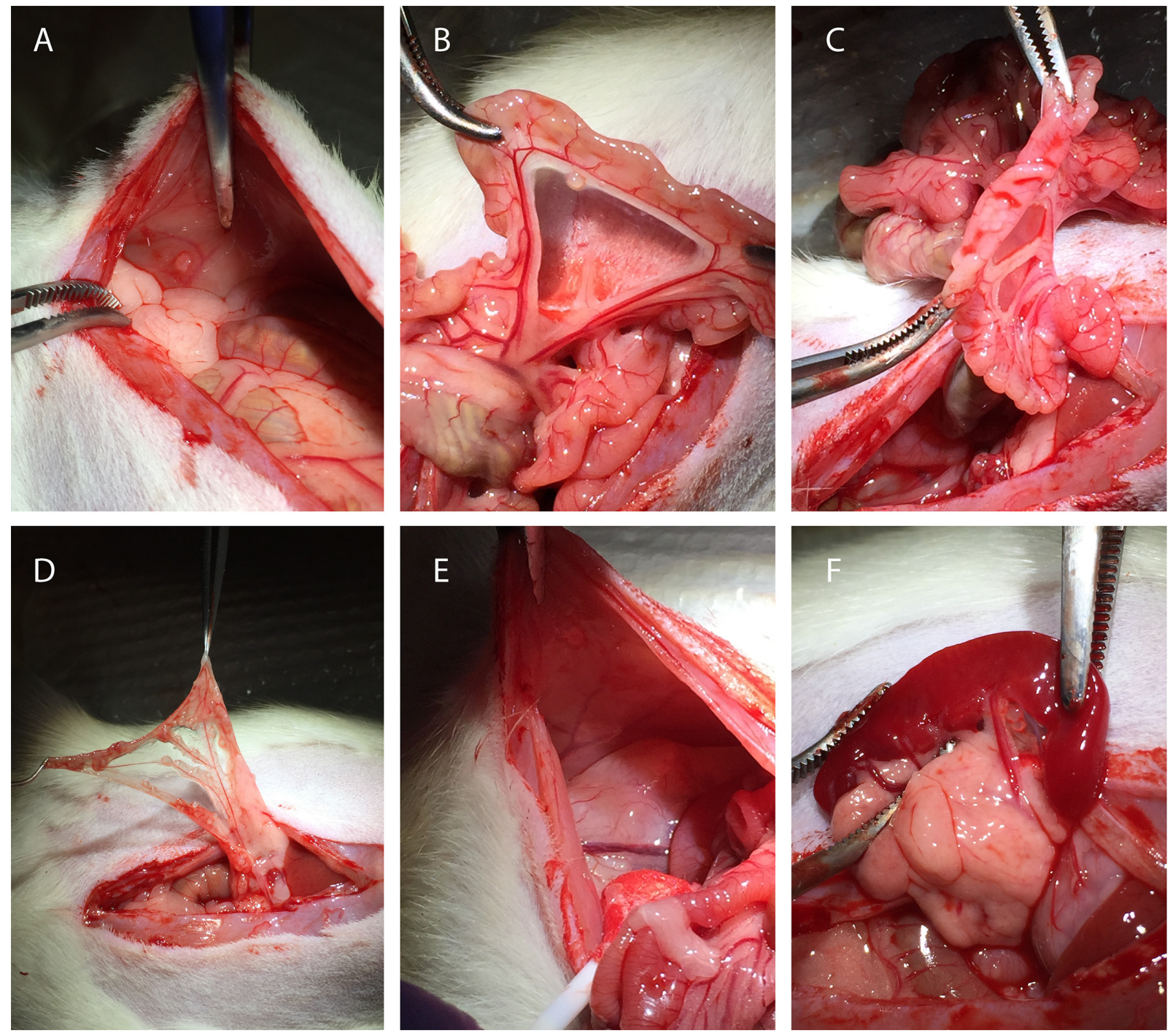

Figure 2: Macroscopic peritoneal tumor nodules found during laparotomy. (A) injection site; (B) mesentery; (C) bowel surface; (D) greater omentum; (E) right abdominal fat pad; (F) spleen. 
Other non-tumor-related causes of death, within 2 days after CRS and HIPEC, were organ failure and bowel obstruction.

PCI score at autopsy was significantly lower in rats treated with CRS and HIPEC as compared to rats treated with CRS alone $(p<0.001)$ (Table 2$)$. Within each treatment group, PCI was significantly lower at autopsy as compared to day of treatment when rats received CRS and HIPEC-CONC $(p<0.001)$ and CRS and HIPEC$\operatorname{BSA}(p=0.002)$. In contrast, when rats were treated with CRS alone, PCI at autopsy was significantly higher as compared to the PCI score at day of treatment $(p<0.001)$. In the latter group, significantly more volume of ascites was drained at autopsy $(p<0.001)$, and hemorrhagic ascites was therefore the most common reason for reaching the humane endpoint is this treatment group. Other reasons for ending the experiment were significant weight loss, diarrhea and palpable tumor nodules in the abdomen or subcutaneously. Using Cox survival regression analysis, no confounding factors influencing survival could be identified. Variables considered were modified PCI, R-score, AUC plasma, AUC peritoneal fluid, $\mathrm{PA}$ and $\mathrm{Pt}$ concentration in the tumor nodule at the end of HIPEC.

\section{DISCUSSION}

This is the first preclinical animal study designed to build pharmacologic data towards an improved and standardized HIPEC procedure, focusing on the dosimetry of IP chemotherapy. Using validated assays, we report that there is no difference in PA, defined as the ratio of AUC peritoneal fluid over AUC plasma, between BSAbased and concentration-based HIPEC. However, proof of principle is provided, that a higher IP concentration of the chemotherapeutic drug in concentration-based HIPEC results in a higher drug concentration in the tumor nodule at the end of HIPEC.

The Wag/Rij rat injected with the syngeneic CC531 cell line is a widely used, validated and reproducible animal model of colorectal PSM, which resembles the clinical situation [13]. In the past, this preclinical model has frequently been used in combination with IP mitomycin $C$, the alternative HIPEC drug in the treatment of colorectal PSM [14-17]. Several research groups used the CC-531 cell line in combination with oxaliplatin [18-22]. However, as they did not include a cell viability assay to investigate sensitivity of the

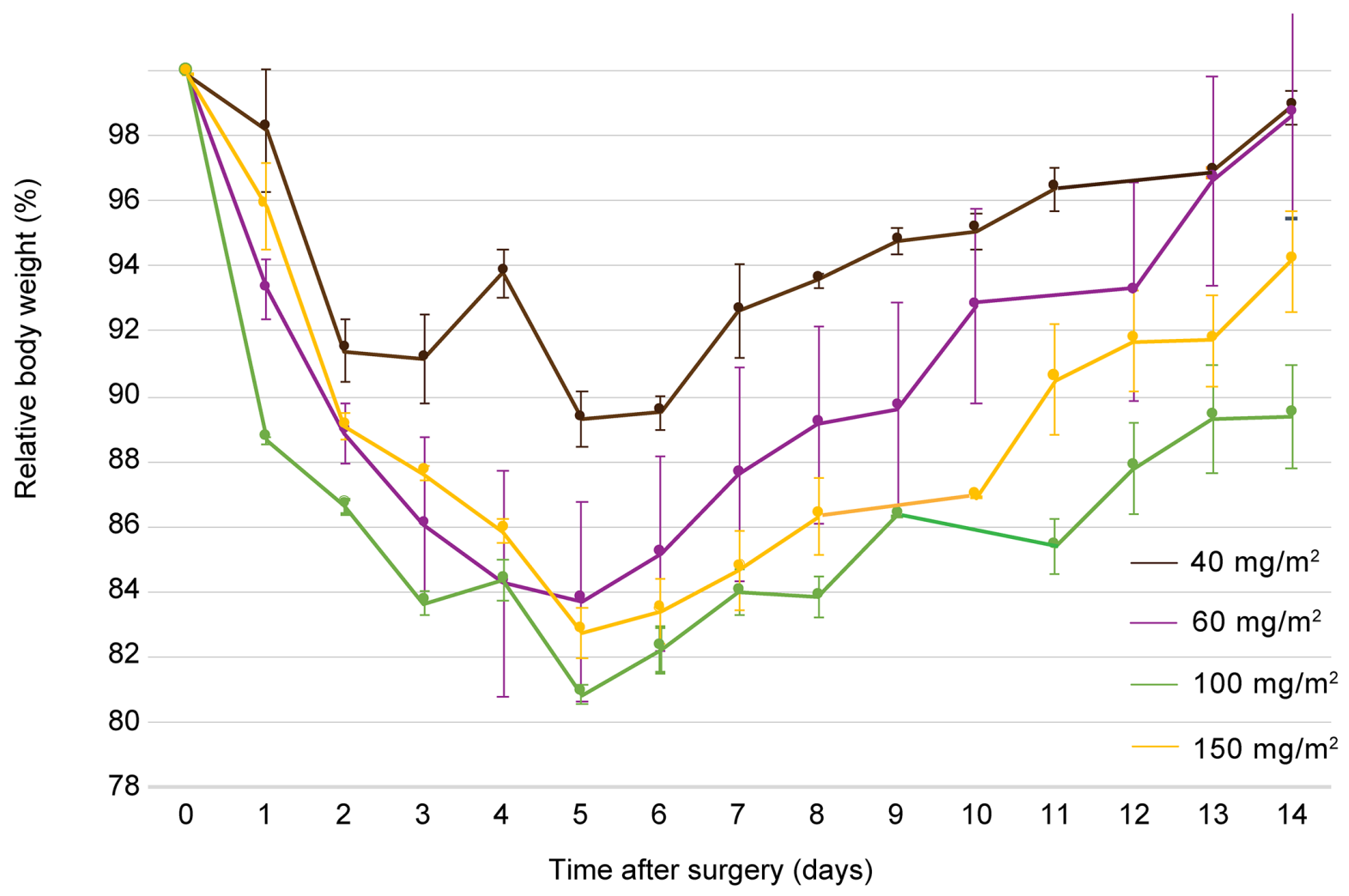

Figure 3: Evolution of mean body weight, relative to the weight at day of treatment, 14 days after surgery of rats treated with CRS and HIPEC to determine the maximum tolerated dose of oxaliplatin during HIPEC. Rats were treated with $40 \mathrm{mg} / \mathrm{m}^{2}$ (brown), $60 \mathrm{mg} / \mathrm{m}^{2}$ (purple), $100 \mathrm{mg} / \mathrm{m}^{2}$ (green) and $150 \mathrm{mg} / \mathrm{m}^{2}$ (yellow) oxaliplatin. CRS, cytoreductive surger; HIPEC, hyperthermic intraperitoneal perioperative chemotherapy. Values are mean $\pm \mathrm{SE}$. 
Table 1: Modified peritoneal cancer index score before cytoreductive surgery

\begin{tabular}{|c|c|c|c|}
\hline Subgroup & $\begin{array}{c}\text { CRS } \\
(n=21)\end{array}$ & $\begin{array}{l}\text { HIPEC-BSA } \\
\quad(n=21)\end{array}$ & $\begin{array}{c}\text { HIPEC-CONC } \\
(n=21)\end{array}$ \\
\hline \multicolumn{4}{|l|}{ Tumour score per site ${ }^{a}$} \\
\hline Subcutaneous & $0(0-3)$ & $0(0-3)$ & $0(0-0)$ \\
\hline Injection site & $0(0-3)$ & $1(0-1)$ & $1(0-1)$ \\
\hline Greater omentum & $2(0-2)$ & $1(0-1)$ & $2(1-2)$ \\
\hline Liver hilum & $2(0-2)$ & $1(0-3)$ & $2(1-3)$ \\
\hline Liver & $0(0-0)$ & $0(0-0)$ & $0(0-0)$ \\
\hline Perisplenic & $1(1-2)$ & $1(0-2)$ & $1(1-3)$ \\
\hline Mesentery & $1(0-1)$ & $1(0-3)$ & $1(0-3)$ \\
\hline Bowel surface & $1(1-1)$ & $1(0-1)$ & $1(1-3)$ \\
\hline Abdominal fat pads & $0(0-0)$ & $3(0-3)$ & $0(0-3)$ \\
\hline Gonadal fat pads & $1(0-3)$ & $1(1-3)$ & $2(1-3)$ \\
\hline Diaphragm & $0(0-1)$ & $0(0-0)$ & $0(0-2)$ \\
\hline Parietal peritoneum & $0(0-1)$ & $0(0-3)$ & $0(0-1)$ \\
\hline Mean $\mathrm{PCI}^{\mathrm{b}}$ & $8.1(2.4)$ & $9.7(2.3)$ & $11.5(2.0)$ \\
\hline \multicolumn{4}{|c|}{$\begin{array}{l}\text { Completeness of resection } \\
\text { (n) }\end{array}$} \\
\hline $\mathrm{R} 1$ & 0 & 0 & 0 \\
\hline $\mathrm{R} 2 \mathrm{a}$ & 14 & 14 & 17 \\
\hline $\mathrm{R} 2 \mathrm{~b}$ & 7 & 7 & 4 \\
\hline
\end{tabular}

CRS, cytoreductive surgery; HIPEC, hyperthermic intraperitoneal perioperative chemotherapy; BSA, body surface area; PCI, peritoneal cancer index. Values are amedian (range), ${ }^{b}$ mean (SD); 0, no macroscopic tumor; 1 , limited tumor growth (1-2 mm Ø); 2, moderate tumor growth (2-4 mm Ø); 3, abundant presence of tumor nodules ( $>4 \mathrm{~mm} \varnothing)$; the sum of scores from all sites represent the overall modified PCI. Completeness of resection after CRS; R1, absence of residual tumor; R2a, residual tumor of $2.5 \mathrm{~mm}$ or less; R2b, residual tumor larger than $2.5 \mathrm{~mm}$.

cell line for oxaliplatin, we performed a MTT assay and report the CC-531 cell line to be sensitive for oxaliplatin.

The syngeneic rat model of colorectal PSM enables one to quantify the extent of disease using the modified PCI score, perform surgery and HIPEC procedures, both open and closed $[14,23]$. To create a standardized experimental model, we decided to surgically remove the greater omentum, spleen and gonadal fat pads by default. Additionally, macroscopic tumor deposits on the abdominal fat pads and other locations were removed or cauterized when possible, but no bowel resections or anastomoses were made. In our study design, it was therefore not feasible to achieve a R1 score, a complete macroscopic resection. However, tumor nodules left on the bowel surface were 1 to $2 \mathrm{~mm}$ in size, which is within penetration depth of oxaliplatin [24]. HIPEC in the animal model was performed by the open technique with a perfusion time of 30 minutes which mimics the current clinical setting in our institute. A disadvantage of using the open HIPEC technique in this animal model when compared to the closed technique, is that the target temperature of $41.5^{\circ} \mathrm{C}$ could not be reached without increasing the overall body temperature of the rats. Therefore, in this setting, HIPEC was performed at a median temperature of $40.3^{\circ} \mathrm{C}$.

Initially, Hribaschek and colleagues reported the use of an IP oxaliplatin dose of $80 \mathrm{mg} / \mathrm{m}^{2}$ (BSA-based), but due to high mortality rates in the animals, they reduced the dose to $60 \mathrm{mg} / \mathrm{m}^{2}$. Grémonprez et al. determined $150 \mathrm{mg} /$ $\mathrm{m}^{2}$ oxaliplatin in $2 \mathrm{~L} / \mathrm{m}^{2}$ carrier solution (concentrationbased) to be the MTD in a mouse model of colorectal PSM [25]. To determine MTD of oxaliplatin in our animal model, we used doses of oxaliplatin ranging from 40 to $150 \mathrm{mg} / \mathrm{m}^{2}$ in $2 \mathrm{~L} / \mathrm{m}^{2}$, the latter being approximately $1 / 3$ of the clinical high dose of $460 \mathrm{mg} / \mathrm{m}^{2}$ [26]. Figure 3 presents that rats treated with $100 \mathrm{mg} / \mathrm{m}^{2}$ lose more weight in the 14-day postoperative period when compared to rats treated with $150 \mathrm{mg} / \mathrm{m}^{2}$ oxaliplatin, although not significant. 
However, we defined $150 \mathrm{mg} / \mathrm{m}^{2}$ in $2 \mathrm{~L} / \mathrm{m}^{2}$ as the MTD for future experiments because the PCI score at autopsy was the lowest in this treatment group. Furthermore, no blood sampling was performed during the MTD experiments and we expected this to further increase the weight reduction after CRS and HIPEC.

To pharmacologically evaluate the two dosing regimens that are used as standard of care in current clinical practice, we designed an animal study where rats were treated with $\mathrm{CRS}$ alone or CRS combined with HIPEC either BSA-based or concentration-based. The modified PCI score at day of treatment was significantly higher in the HIPEC-CONC group, but after surgery completeness of resection was similar in all treatment groups. In the HIPEC-CONC group, as every rat was treated with the same oxaliplatin concentration, we did not expect the large SD $(22.08 \pm 7.65 \mu \mathrm{g} / \mathrm{mL})$ of the $\mathrm{Pt}$ concentration in the peritoneal fluid at the start of HIPEC (Figure 5). This Pt concentration variability suggests that 2 minutes homogenization is not sufficient. The $\mathrm{Pt}$ concentration measured in the peritoneal fluid sample taken at the start of the 30-minute HIPEC clock was only $63.65 \pm 17.12 \%$ of the theoretical Pt concentration administered in the HIPEC reservoir. One could argue to prolong the homogenization period, but this will lead to loss of information in the plasma compartment as $\mathrm{Pt}$ levels, found at the beginning of HIPEC, are far above the limit of quantification of the ICP-MS method. Moreover, a longer homogenization period will increase systemic hyperthermia. Another possible solution, to overcome the need for homogenization of the chemotherapy solution, is to already dilute oxaliplatin in the carrier solution in a large reservoir before HIPEC treatment. However, $0.9 \%(\mathrm{w} / \mathrm{v}) \mathrm{NaCl}$ was used in our experimental design as carrier solution and it is known that oxaliplatin undergoes degradation in chloride-containing solutions [27]. This degradation is nonetheless limited to approximately $10 \%$ after 30 minutes and degradation is believed to

42

40

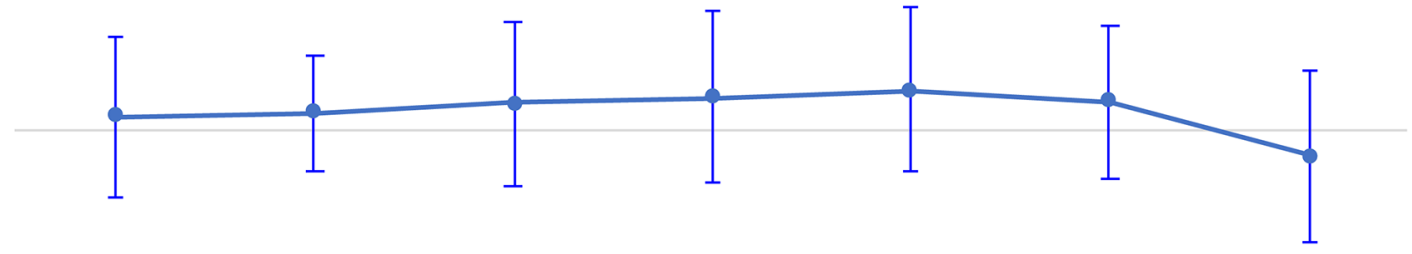

38

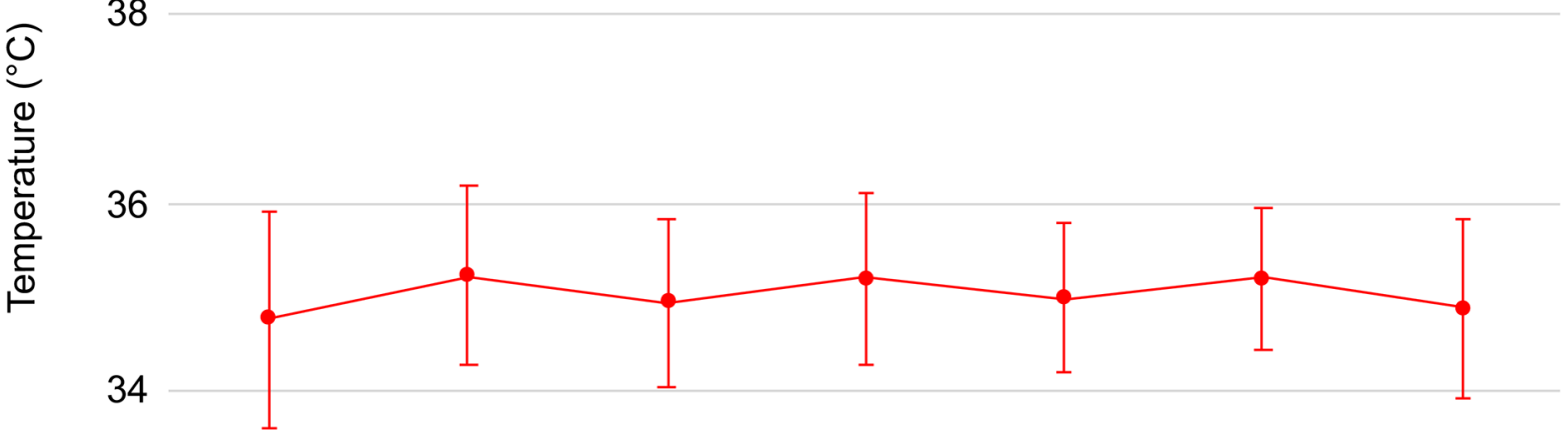

32

Intra-abdominal temperature

Rectal temperature

30

\begin{tabular}{lcccccc}
\hline 0 & 5 & 10 & 20 & 25 & 30 \\
& Time (minutes)
\end{tabular}

Figure 4: Intra-abdominal and rectal temperatures monitored during hyperthermic intraperitoneal perioperative chemotherapy. Intra-abdominal temperatures $\left({ }^{\circ} \mathrm{C}\right)$ are depicted in blue and rectal temperatures $\left({ }^{\circ} \mathrm{C}\right)$ are depicted in red. Values are mean $\pm \mathrm{SD}(\mathrm{n}=42)$. 


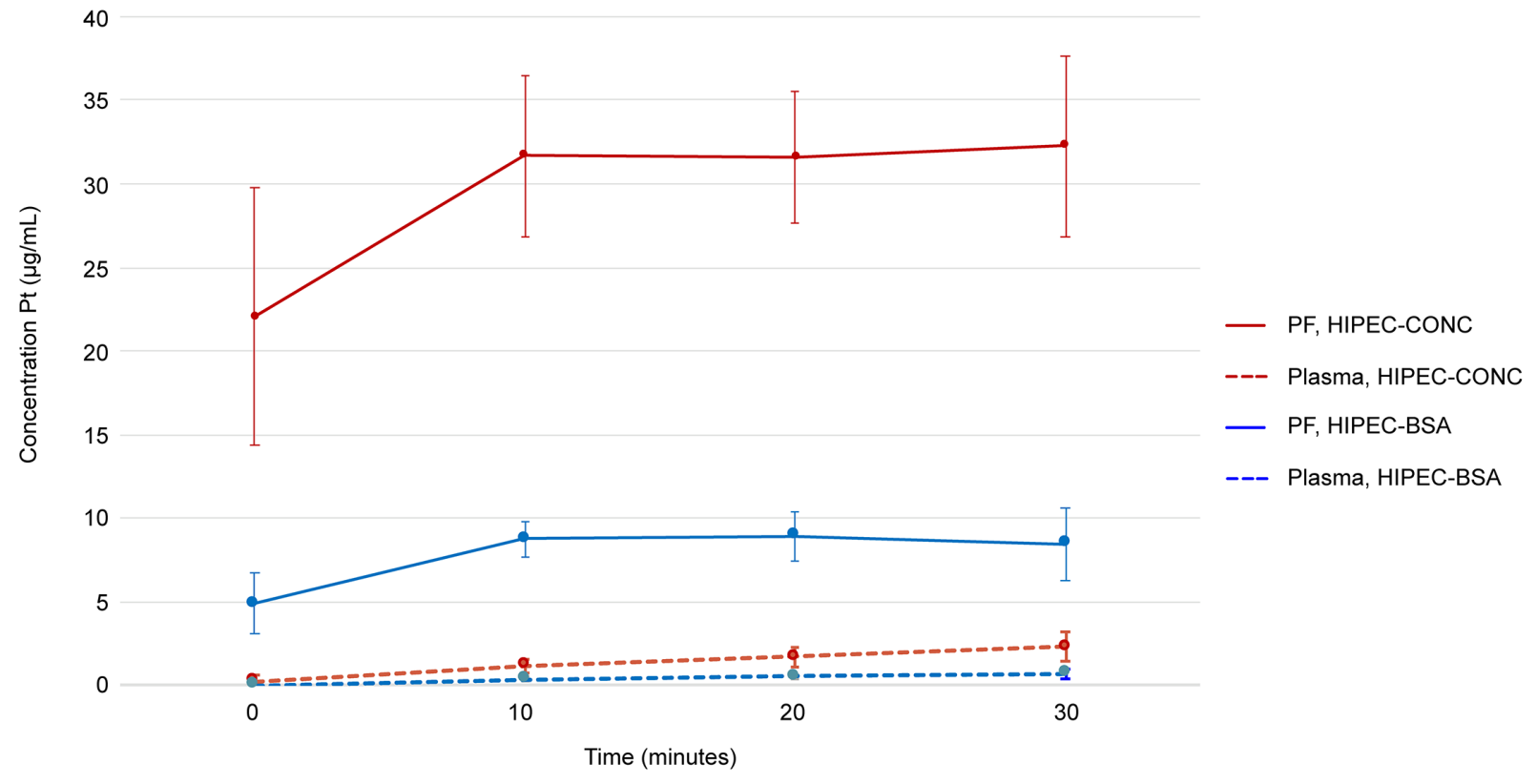

\begin{tabular}{|c|c|c|c|}
\hline & HIPEC-BSA & HIPEC-CONC & $p$ value \\
\hline AUC plasma & $13.07 \pm 3.95$ & $41.66 \pm 12.39$ & $<0.001$ \\
\hline AUC PF & $243.91 \pm 24.34$ & $903.97 \pm 128.44$ & $<0.001$ \\
\hline PA & $19.58(15.57-21.04)$ & $19.61(16.89-26.98)$ & 0.283 \\
\hline
\end{tabular}

Figure 5: Pharmacokinetic graph of oxaliplatin-derived Pt in peritoneal fluid and plasma during the 30-minute HIPEC. Pt concentrations in peritoneal fluid (PF, full line) and plasma (dotted line) of rats treated with concentration-based HIPEC are depicted in red. Pt concentrations in PF (full line) and plasma (dotted line) of rats treated with BSA-based HIPEC are depicted in blue. Pt, platinum; PF, peritoneal fluid; HIPEC, hyperthermic intraperitoneal perioperative chemotherapy; AUC, area-under-the curve; BSA, body surface area; PA, pharmacologic advantage. Values are mean $\pm \mathrm{SD}$ ( $\mathrm{n}=21$ per group).
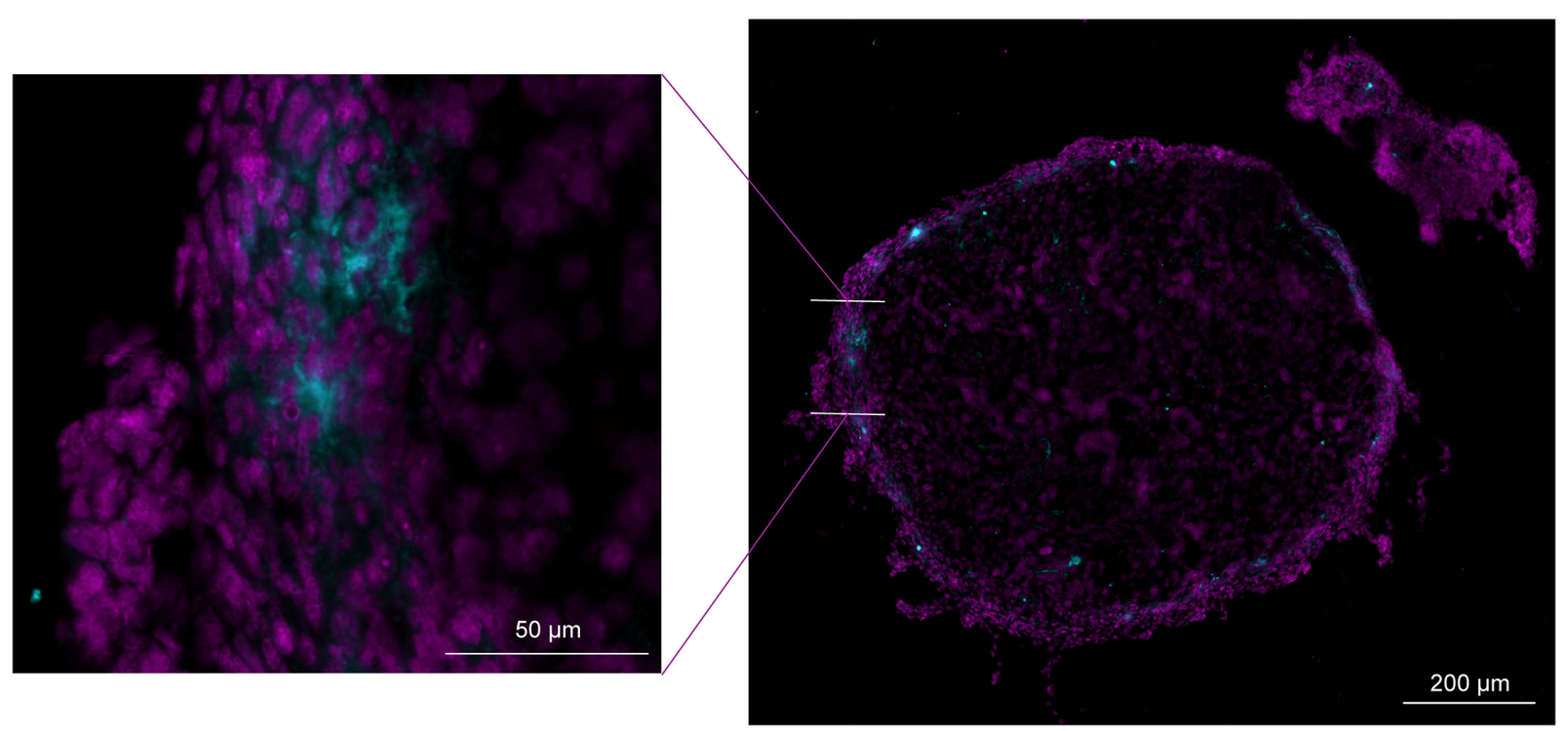

Figure 6: Representative image of immunohistochemistry staining for activated caspase-3. Cross section (10 $\mu \mathrm{m}$ thick) of inner layer of a greater omentum tumor nodule of a rat treated with BSA-based HIPEC. DAPI staining (magenta) and activated caspase-3 staining (cyan). BSA, body surface area; HIPEC, hyperthermic intraperitoneal perioperative chemotherapy. 
promote the formation of its active cytotoxic drug form. Pre-mixing of the chemotherapy solution will also not allow to reach stable perfusion conditions, such as stable hyperthermia, before starting chemotherapy treatment. Pharmacokinetics of IP drug delivery can be described by a simple 2-compartment model [28]. This model comprises a systemic compartment (characterized by a drug concentration and distribution volume) and a peritoneal compartment (characterized by a perfusate concentration and volume). As the peritoneal compartment is the biggest compartment, a possible recommendation would be to administer the drug directly in the peritoneal cavity to facilitate homogenization of the chemotherapy solution. This recommendation overcomes the previously mentioned drawbacks of prolonging the homogenization period, i.e. loss of information in the systemic compartment and risk of systemic hyperthermia. These findings might also have a profound implication on current clinical practice.

The ideal drug for IP drug delivery has a high peritoneal tissue concentration (high AUC of the peritoneal fluid compartment) and high penetration in the tumor nodule. This should occur in conjunction with slow diffusion of the chemotherapy solution through the peritoneal membrane and deep in the subperitoneal space, resulting in low systemic exposure (low AUC of the plasma compartment) [6]. In this setting, the AUC of the peritoneal fluid compartment reflects efficacy of the drug and the AUC of the systemic compartment reflects toxicity. This explains why the PA has been used as a parameter to assess the potential of a given drug to be used during HIPEC [28]. Systemic and peritoneal fluid Pt levels were significantly different between the HIPECBSA and HIPEC-CONC treatment groups. Nevertheless, concerning the primary endpoint of our preclinical study, this did not result in a significant difference in PA between the HIPEC treatment groups. However, at the same time we found higher levels in the tumor nodule in the HIPEC-CONC group. These data clearly demonstrate that the PA does not provide any information about the amount of chemotherapy reaching the tumor nodule in the peritoneal cavity. We provide proof of principle that a higher concentration of the chemotherapeutic drug in the peritoneal fluid (HIPEC-CONC), results in a higher concentration of the drug in the tumor nodule at the end of the 30-minute HIPEC procedure. Therefore, the tumor nodule should be considered the pharmacologic endpoint rather than the PA of a drug.

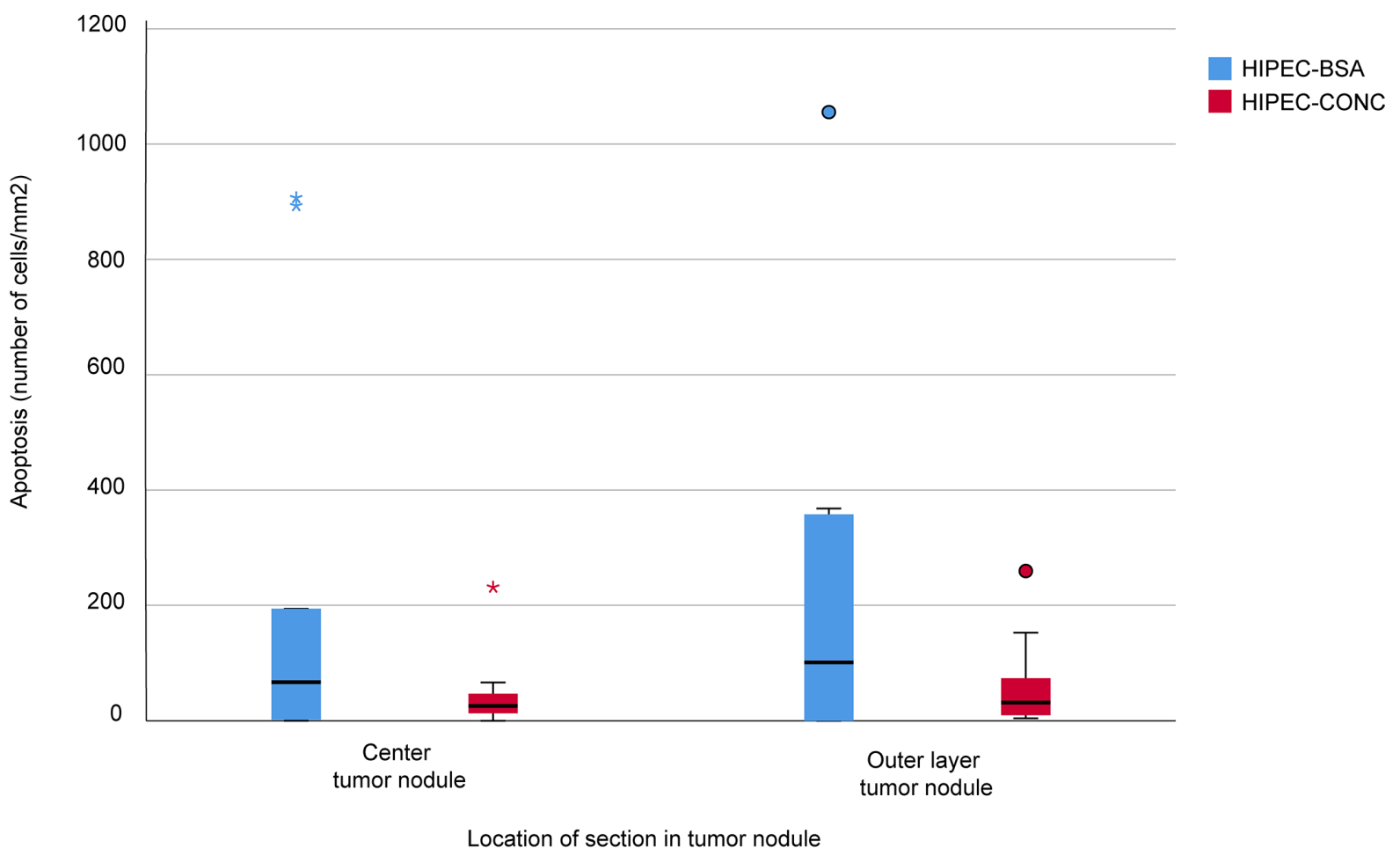

Figure 7: Apoptosis measurements. Apoptosis in the center and outer layer of the tumor nodule was evaluated in rats treated with concentration-based HIPEC (HIPEC-CONC, $\mathrm{n}=10$, red) and BSA-based HIPEC (HIPEC-BSA, n=10, blue) by means of immunohistochemistry for activated caspase-3. Median number of cells $/ \mathrm{mm}^{2}$ was $25.56(13.16-46.5)$ in the center and $31.70(9.47-$ $73.73)$ in the outer layer of the tumor nodule in the HIPEC-CONC group. In the HIPEC-BSA group, median number of cells $/ \mathrm{mm}^{2}$ was 66.84 $(1.67-194.29)$ in the center of the tumor nodule and $131.06(10.67-357.62)$ in the outer layer of the nodule. 
The next logical step was to investigate if a higher drug concentration in the tumor nodule also results in a higher amount of apoptosis. In this setting, apoptosis was considered a measure to comprehend all pharmacodynamic effects. Recent insights into the tumor biology suggest that pharmacodynamic parameters (vascularity, IFP, extracellular matrix properties, etc.) are at least as important in tumor response to chemotherapy as the pharmacokinetics mentioned above [29]. As a pilot study, we assessed the amount of cell death in the center and outer layer of 10 tumor nodules in each of the HIPEC treatment groups by means of IHC staining for activated caspase-3. Statistical analysis did not demonstrate a significant difference in amount of apoptosis in both layers of the tumor nodule treated with either BSA-based or concentration-based HIPEC. Although no difference in the amount of apoptotic cells could be detected, the range of apoptosis is smaller in the HIPEC-CONC group. This is as expected as every tumor nodule in this treatment group received a fixed concentration of oxaliplatin (75 $\mathrm{mg} / \mathrm{L}$, i.e. $150 \mathrm{mg} / \mathrm{m}^{2}$ in $2 \mathrm{~L} / \mathrm{m}^{2}$ ). Although not confirmed by statistical analysis, there is a trend towards more apoptotic cells per $\mathrm{mm}^{2}$ in the outer layer when compared to in the center of the tumor nodule. The clinical implications of this apoptotic pilot study are very limited but nevertheless very important in that it is hypothesis generating. As tumor nodules were sampled at the end of the 30-minute HIPEC procedure, we should consider that at that point in time an effect of the drug cannot be detected. A limitation of this pilot study is that, due to practical reasons, it was not possible to sample tumor nodules at later time points after HIPEC, to evaluate apoptosis. Another limitation is that no sound conclusion can be made if the demonstrated apoptosis is due to the CRS or to the HIPEC part of the combined therapy; as no tumor nodules for apoptosis quantification were sampled in the CRS-only group.

In contrast to a previous preclinical study conducted by Klaver et al. [30], we could not demonstrate a median survival benefit for the HIPEC treatment groups when compared to the CRS group. A possible explanation could be the choice of drug, as Klaver and colleagues used mitomycin $\mathrm{C}$ as the chemotherapeutic agent in their HIPEC procedure. In our study, all rats in the CRS group survived the surgery, whereas 4 rats in the HIPEC-CONC group did not wake up from anesthesia and others in the HIPEC treatment groups died from organ failure or bowel obstruction. This can be explained by the fact that in the CRS group, the duration of anesthesia was

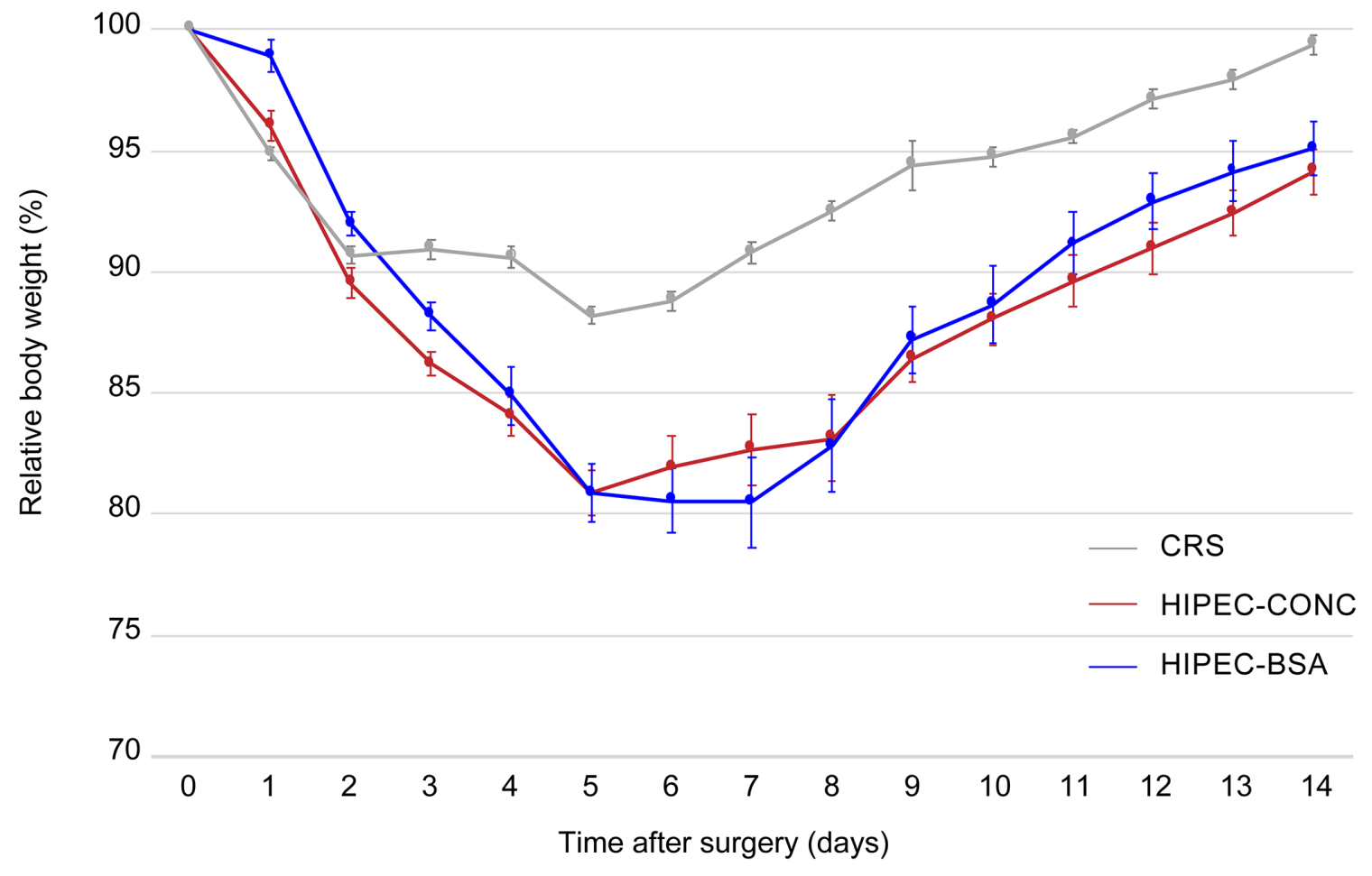

Figure 8: Evolution of mean body weight, relative to the weight at day of treatment, 14 days after surgery. Relative body weight of rats treated with either CRS alone is depicted in grey, treated with CRS and HIPEC concentration-based (HIPECCONC) depicted in red and treated with CRS and HIPEC BSA-based (HIPEC-BSA) depicted in blue. CRS, cytoreductive surgery; HIPEC, hyperthermic intraperitoneal perioperative chemotherapy; BSA, body surface area. Values are mean \pm SE. 
much shorter as compared to the HIPEC groups and no sampling was performed. Furthermore, the mean weight during the 14-day postoperative period, reflecting treatment-related toxicity, was also more pronounced in the HIPEC groups. However, when looking at the PCI score at autopsy, the extent of disease was significantly lower when rats were treated with CRS and HIPEC as compared to CRS alone. Furthermore, within each treatment group, PCI was significantly lower at autopsy as compared to day of treatment when rats received CRS and HIPEC. Regarding weight loss, extent of disease and survival, there was no difference between rats treated with BSA-based or concentration-based HIPEC. We concluded that clinical parameters, including weight loss and extent of disease are not predictive for tumor response.

In conclusion, this study clearly demonstrates that there is no difference in PA between BSA-based and concentration-based HIPEC. Moreover, the PA does not provide any information about the true pharmacodynamic efficacy of the drug to treat the tumor nodule in the peritoneal cavity. We provide proof of principle that a higher IP concentration of the chemotherapeutic drug in the concentration-based HIPEC results in a higher concentration of the drug in the tumor nodule at the end of the 30-minute HIPEC procedure. We emphasize the importance of considering the tumor nodule as the pharmacologic endpoint rather than the PA of the drug. We considered apoptosis as a potential pharmacodynamic endpoint in order to try to correlate pharmacokinetic and pharmacodynamic parameters in determining tumor response. The next step is the translation of the optimization and standardization of the HIPEC dosing regimen in a clinical setting taking into account the individual drug sensitivity in the treatment of PSM.

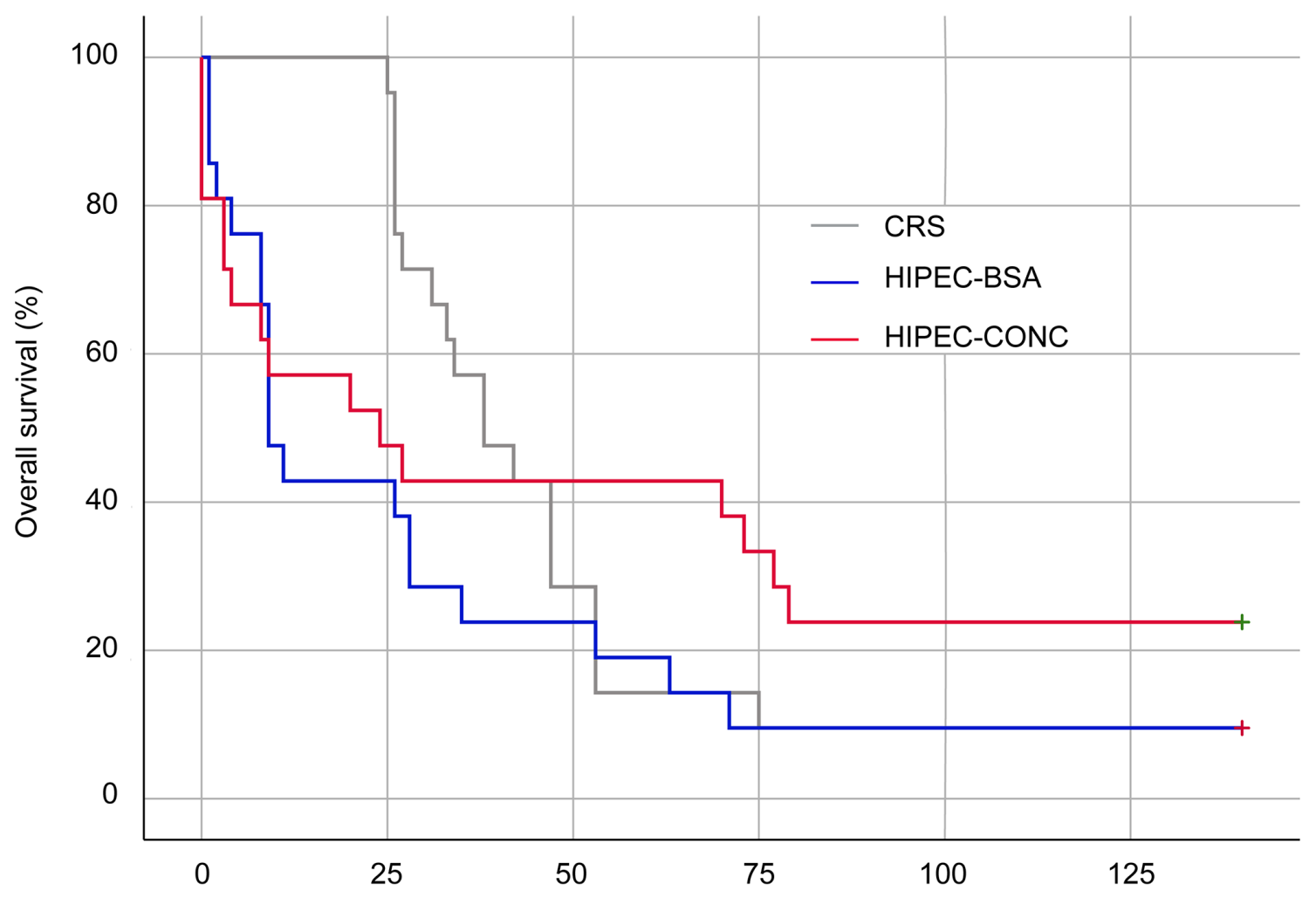

Number at risk

$\begin{array}{rr}\text { CRS } & 21 \\ \text { HIPEC-BSA } & 21 \\ \text { HIPEC-CONC } & 21\end{array}$

Figure 9: Kaplan-Meir curves. Survival curves are presented of rats treated with CRS only (grey), CRS combined with HIPEC, BSAbased (blue) and CRS combined with HIPEC, concentration-based (red). CRS, cytoreductive surgery; HIPEC, hyperthermic intraperitoneal perioperative chemotherapy; BSA, body surface area. 
Table 2: Modified peritoneal cancer index score at autopsy

\begin{tabular}{|c|c|c|c|}
\hline Subgroup & $\begin{array}{c}\text { CRS } \\
(n=17)\end{array}$ & $\begin{array}{c}\text { HIPEC-BSA } \\
(n=21)\end{array}$ & $\begin{array}{c}\text { HIPEC-CONC } \\
(n=19)\end{array}$ \\
\hline \multicolumn{4}{|l|}{ Tumour score per site ${ }^{a}$} \\
\hline Subcutaneous & $3(0-3)$ & $0(0-3)$ & $0(0-3)$ \\
\hline Injection site & $2(0-3)$ & $1(0-3)$ & $1(0-3)$ \\
\hline Greater omentum & $0(0-0)$ & $0(0-0)$ & $0(0-0)$ \\
\hline Liver hilum & $3(0-3)$ & $0(0-3)$ & $0(0-3)$ \\
\hline Liver & $1(0-3)$ & $0(0-0)$ & $0(0-1)$ \\
\hline Perisplenic & $0(0-3)$ & $0(0-0)$ & $0(0-0)$ \\
\hline Mesentery & $2.5(0-3)$ & $0(0-3)$ & $0(0-3)$ \\
\hline Bowel surface & $1(1-3)$ & $1(1-3)$ & $1(0-3)$ \\
\hline Abdominal fat pads & $3(0-3)$ & $1(0-3)$ & $0(0-3)$ \\
\hline Gonadal fat pads & $3(0-3)$ & $0(0-3)$ & $0(0-3)$ \\
\hline Diaphragm & $3(0-3)$ & $0(0-3)$ & $0(0-3)$ \\
\hline Parietal peritoneum & $1(0-3)$ & $0(0-1)$ & $0(0-3)$ \\
\hline Mean PCI ${ }^{\mathrm{a}}$ & $19(11-22)$ & $3(3-7)$ & $3(2-5)$ \\
\hline Volume of ascites $(\mathrm{mL})^{\mathrm{a}}$ & $55(0-65)$ & $0(0-0)$ & $0(0-3)$ \\
\hline
\end{tabular}

CRS, cytoreductive surgery; HIPEC, hyperthermic intraperitoneal perioperative chemotherapy; BSA, body surface area; PCI, peritoneal cancer index. Values are amedian (range); 0, no macroscopic tumor; 1, limited tumor growth (1-2 mm Ø); 2 , moderate tumor growth $(2-4 \mathrm{~mm} \varnothing) ; 3$, abundant presence of tumor nodules ( $>4 \mathrm{~mm} \varnothing)$; the sum of scores from all sites represent the overall modified PCI.

\section{MATERIALS AND METHODS}

\section{Ethics statement}

Research has been conducted in accordance with the ethical standards, conforming to the EU Directive 2010/63/EU for animal experiments and was approved by the local Ethical Committee for Animal Experiments at Hasselt University, Belgium (protocol number: 201734).

\section{Safety considerations}

When working with chemotherapeutic agents, standard safety precautions were applied. These include wearing personal protective equipment (eye protection, protective gloves, mouth mask and protective clothing) and using standardized handling procedures, including the use of BD PhaSeal ${ }^{\mathrm{TM}}$ closed system transfer devices (Dublin, Ireland), to minimize chemotherapy associated exposure risks. All chemotherapy associated materials and animal samples were disposed in WIVA medical waste containers.

\section{Cancer cell line}

\section{Cell culture}

The syngeneic rat colorectal carcinoma CC531 cell line was kindly provided by the Research Laboratorium Surgery of the Radboud University Medical Center in the Netherlands. Cells were cultured in RPMI 1640 medium (BE12-115F/U1, BioWhittaker ${ }^{\circledR}$, Lonza, Verviers, Belgium), supplemented with $10 \%$ fetal bovine serum (FBS, Gibco ${ }^{\circledR}$, Life Technologies, Paisley, UK) and $1 \%$ penicillin-streptomycin (Sigma-Aldrich, St. Louis, Missouri, USA), under standardized incubator conditions, $37^{\circ} \mathrm{C}$ and $5 \% \mathrm{CO}$. Cell suspensions were prepared after enzymatic detachment with trypsin-EDTA solution (Sigma-Aldrich, St. Louis, Missouri, USA). Subsequently, the cell suspension was centrifuged at $1000 \mathrm{rpm}$ for 2 minutes and resuspended in supplemented RPMI 1640 medium to reach the required concentration. Cell suspensions for animal injection were resuspended in $2 \mathrm{~mL}$ phosphate buffer saline (PBS) solution (BE17-516F, BioWhittaker ${ }^{\circledR}$, Lonza, Verviers, Belgium) at a concentration of $10^{6}$ cells $/ \mathrm{mL}$. 


\section{Oxaliplatin in vitro cytotoxicity}

Viability of the CC-531 cell line after oxaliplatin (5 mg/ml Eloxatin ${ }^{\circledR}$, Sanofi, Diegem, Belgium) treatment was evaluated in vitro by the colorimetric MTT assay. CC-531 cells were seeded in 96-well plates (Cellstar ${ }^{\circledR}$, Greiner Bio-One GmbH, Frickenhausen, Germany) at a density of 8000 cells $/ 100 \mu \mathrm{L} /$ well and incubated at $37^{\circ} \mathrm{C}, 5 \% \mathrm{CO} 2$ for $24 \mathrm{~h}$. Medium was replaced by 200 $\mu \mathrm{L}$ oxaliplatin, 10 -fold diluted in medium to reach concentrations of $20 \mu \mathrm{g} / \mathrm{mL}, 30 \mu \mathrm{g} / \mathrm{mL}, 50 \mu \mathrm{g} / \mathrm{mL}$ and $75 \mu \mathrm{g} / \mathrm{mL}$; corresponding to the following dosages of $40 \mathrm{mg} / \mathrm{m}^{2}, 60 \mathrm{mg} / \mathrm{m}^{2}, 100 \mathrm{mg} / \mathrm{m}^{2}$ and $150 \mathrm{mg} / \mathrm{m}^{2}$, in 2 $\mathrm{L} / \mathrm{m}^{2}$. Next, the plates were incubated at standardized incubator conditions for 30 minutes. Subsequently, the chemotherapy solution was replaced by $200 \mu \mathrm{L}$ medium and incubated at standardized incubator conditions for 24 hours. Afterwards, $10 \mu \mathrm{L}$ MTT solution (Life Technologies, Eugene, Oregon, USA) was added and incubated at standardized incubator conditions for $4 \mathrm{~h}$, protected from light. The medium was removed and the formazan crystals were dissolved in $100 \mu \mathrm{L}$ sodium dodecyl sulfate (SDS, Life Technologies, Eugene, Oregon, USA). Eight wells per concentration were used and all experiments were performed in triplicates. The absorbance of samples was measured at $570 \mathrm{~nm}$ with a FLUOstar $^{\circledR}$ Omega microplate reader (BMG Labtech, Offenburg, Germany). Cell viability of oxaliplatin treated cells compared to control cells, treated with medium without the chemotherapeutic agent, was expressed in percentages.

\section{Animals and housing}

Ten weeks old male WAG/Rij rats with a median weight of 236.6 (219.8 - 248.10) g were obtained from Charles River Laboratories (Calco, Italy). Rats were accustomed to laboratory conditions for 1 week before experimental use and housed under clean, nonsterile standardized conditions (temperature $22^{\circ} \mathrm{C}, 12 \mathrm{~h}$ light/12h dark) in Eurostandard type IV open-top cages (three rats per cage) with autoclaved sawdust bedding and cage enrichment. The animals were allowed free access to food (2018 Teklad global 18\% protein rodent diet, Envigo, Madison, Wisconsin, USA) and acidified water.

\section{Anesthesia}

All experiments; i.e. induction of PSM, CRS and HIPEC were performed under anesthesia using a mixture of isoflurane (IsoFlo ${ }^{\circledR}$, Zoetis, Louvainla-Neuve, Belgium), $1-2 \%$ volume supplemented with oxygen. Anesthesia was induced in an induction chamber (3.5\% volume supplemented with oxygen) and continued by a face mask ( $1-2 \%$ volume supplemented with oxygen). Level of anesthesia was assessed by evaluation of motoric response to a toe pinch. During all experiments, rats were put into a supine position onto a heating pad.

\section{Induction of peritoneal surface malignancy}

PSM was induced by IP injection of $2 \mathrm{~mL}$ cell suspension in PBS of the syngeneic colorectal carcinoma rat cell line CC-531 at a concentration of $10^{6}$ cells $/ \mathrm{mL}$. The injection was performed under induction of anesthesia.

\section{Study design}

\section{Maximum tolerated dose}

The MTD of oxaliplatin was evaluated in rats treated with CRS and HIPEC. MTD was defined as the highest non-lethal dose of oxaliplatin at which the humane endpoints were not reached. These included extensive weight loss of more than $20 \%$ compared to the body weight measured at day of operation, during three consecutive days within two weeks. Eight days post IP injection of the CC-531 cell line, 12 rats were randomized to CRS and HIPEC at the following increasing oxaliplatin concentrations: $40,60,100$ and $150 \mathrm{mg} / \mathrm{m}^{2}$ in $2 \mathrm{~L} / \mathrm{m}^{2} 0.9 \%$ (w/v) $\mathrm{NaCl}$ carrier solution.

\section{Body surface area-based versus concentration-based HIPEC}

Eight days after IP injection of the CC-531 cell line, 63 rats were randomized into three groups:

- CRS group $(n=21)$ : exploration and CRS alone.

- HIPEC-BSA group $(n=21)$ : CRS followed by HIPEC using the BSA-based dosing method, total dose of $150 \mathrm{mg} / \mathrm{m}^{2}$ oxaliplatin. BSA of the animals was calculated by means of the Du Bois, Du Bois formula: BSA $=0.007184 \times$ Weight $^{0.425}$ x Height ${ }^{0.725}$ [31].

- HIPEC-CONC group ( $n=21)$ : CRS followed by HIPEC using the concentration-based dosing method, $150 \mathrm{mg} / \mathrm{m}^{2}$ oxaliplatin in $2 \mathrm{~L} / \mathrm{m}^{2}$ carrier solution resulting in a fixed concentration of 75 $\mathrm{mg} / \mathrm{L}$ oxaliplatin.

Primary endpoint was a difference in PA. Secondary endpoints were efficacy and survival.

\section{Cytoreductive surgery}

Eight days after PSM induction, CRS was performed under general anesthesia. Thirty minutes prior to surgery, rats were given a subcutaneous injection of buprenorphine (Temgesic $^{\circledR}$, RB Pharmaceuticals Limited, Berkshire, UK) $0.1 \mathrm{mg} / \mathrm{kg} / \mathrm{day}$, and thereafter once daily until the third postoperative day. First, a midline laparotomy was performed and the abdomen was carefully inspected for tumor growth at 12 different sites (Table 1). Tumor deposits at each site were scored semiquantitatively: 0 
for no macroscopic tumor, 1 for limited tumor growth (1-2 mm Ø), 2 for moderate tumor growth (2-4 mm Ø), or 3 for extensive tumor growth $(>4 \mathrm{~mm} \varnothing)$. The sum of scores from all sites represented the modified PCI, based on the PCI score developed by Sugarbaker to evaluate disease burden $[16,32]$. Subsequently, surgery involved standard omentectomy, splenectomy and resection of the gonadal fat pads using an electrocoagulation device. When macroscopic tumor nodules were found in the abdominal fat pads, the latter were removed aiming at complete macroscopic resection. No bowel resections or anastomoses were made. Residual tumor load was scored using the R1-R2a-R2b classification. Absence of residual tumor was scored as R1, a residual tumor of $2.5 \mathrm{~mm}$ or less was scored as R2a, and a tumor larger than $2.5 \mathrm{~mm}$ as $\mathrm{R} 2 \mathrm{~b}$.

\section{Hyperthermic intraperitoneal perioperative chemotherapy}

HIPEC in rats was performed mimicking the open coliseum technique used in current clinical practice. No warming mattress was used during HIPEC, to avoid systemic hyperthermia. The skin edges of the abdomen were raised and attached to a metal frame using sutures. Two sterile Intrafix ${ }^{\circledR}$ SafeSet infusion drains (B. Braun, Melsungen, Germany) were placed in the abdomen and secured on the frame using sutures. These infusion drains were attached to BD Insyte ${ }^{\mathrm{TM}}$ IV catheter 22-gauge needle covers (381223, Sandy, Utah, USA). The infusion drains were connected to a closed perfusion system containing a total volume of $250 \mathrm{~mL} 0.9 \%(\mathrm{w} / \mathrm{v})$ $\mathrm{NaCl}$ (Baxter, Lessines, Belgium) carrier solution. The inflow and outflow drains were placed at opposite sides of the abdomen to achieve a uniform heat distribution and to avoid microcirculation of the perfusate. The peritoneal perfusate was warmed in a glass bottle using a thermostatically regulated water bath $\left(58^{\circ} \mathrm{C}\right)$, aiming at a perfusate temperature of $41.5^{\circ} \mathrm{C}$. The perfusate was infused into the abdomen at $10 \mathrm{~mL} / \mathrm{min}(33 \mathrm{rpm})$ during 30 minutes, using a 120U/DM2 peristaltic pump (010.6141.M20, Watson-Marlow, Zwijnaarde, Belgium). When stable perfusion conditions were achieved and stable perfusate temperature was reached, oxaliplatin was diluted in the circulating carrier solution to the correct concentration, either BSA-based or concentration-based. An extractor hood was placed above the animal during the perfusion procedure to evacuate drug vapor and protect the researchers present. During HIPEC, rectal and intra-abdominal temperatures were monitored every 5 minutes using a rodent thermometer (BIO-TK8851, Bioseb, Vitrolles, France). At each 10-minute time interval, blood $(400 \mu \mathrm{L})$ and peritoneal fluid $(200 \mu \mathrm{L})$ were sampled for Pt quantification using a previously validated ICP-MS method (see section 4.11) [33]. Blood was sampled by means of jugular vein catherization using the catheter rat jugular vein, PU $3 F r 12 \mathrm{~cm}$, collar at $3.8 \mathrm{~cm}$ (Instech Laboratories, Pennsylvania, USA); allowing repeated sampling. Peritoneal fluid was sampled directly in the abdomen of the rat. Omental tumor nodules were sampled at the end of the 30-minute HIPEC procedure for both ICP-MS analysis and IHC apoptosis quantification (see sections 4.11 and 4.12). HIPEC protocol was standardized to take the first sample 2 minutes after administration of oxaliplatin (start 30-minute perfusion clock) to allow homogenization of the chemotherapy solution. After 30 minutes, the perfusate was evacuated by suction, the infusion drains were discarded and the abdominal wall was closed in two layers using continuous $4 / 0$ polyglactin 910 sutures (Vicryl Rapide ${ }^{\mathrm{TM}}$, Ethicon, Somerville, New Jersey, USA) for the muscular layer and the skin layer. Additional interrupted sutures were placed between the continuous sutures for the skin layer. The animals were given $5 \mathrm{~mL} 0.9 \%$ (w/v) $\mathrm{NaCl}$ subcutaneously for rehydration.

\section{Follow-up}

Rats, treated with CRS and HIPEC (to determine the MTD of oxaliplatin), were observed and weighted daily for 14 days after surgery and thereafter euthanized. Rats of the CRS, HIPEC-BSA and HIPEC-CONC group were observed and weighted daily for 14 days after surgery and two times per week thereafter. To reflect the toxicity of the treatment, body weight was expressed as relative body weight compared with the body weight on the day of surgery. Food was placed on the bottom of the cage and water was supplied using a drinking bottle with a long spout. When the humane endpoints were reached, animals were euthanized by IP injection of $200 \mathrm{~mL} / \mathrm{kg}$ pentobarbital (Val d'hony Verdifarm, Beringen-Paal, Belgium) under induction anesthesia. Humane endpoints included extensive weight loss of more than 20\% (MTD group) or $25 \%$ regarding the body weight measured at day of operation, during 3 consecutive days within two weeks. Other humane endpoints were presentation of abnormal behavior and lack of grooming during 3 days after termination of analgesia. Remaining animals were euthanized 140 days post-surgery, when the study was terminated. When possible, animals were subjected to autopsy and tumor load was evaluated using the modified PCI score as described in section 4.8.

\section{Inductively coupled plasma mass spectrometry}

Pt quantification was performed using a previously validated ICP-MS assay [33]. In summary, after the CRS and HIPEC procedure, blood samples were centrifuged for 10 minutes at $1500 \mathrm{rpm}$ at room temperature. The resulting plasma, peritoneal fluid and tumor nodules were stored at $-80^{\circ} \mathrm{C}$ until day of ICP-MS analysis. Tumor 
nodules were digested in 25\% hydrogen peroxide (Merck KGaA, Darmstadt, Germany) and in nitric acid (J.T. Baker, Avantor Performance Materials, Pennsylvania, United States) using the High Performance Microwave Digestion System from Milestone, Ethos Up. Digestion was performed according to the following schedule: 0-15 minutes, $1800 \mathrm{~W}, \uparrow 200^{\circ} \mathrm{C}$; $15-30$ minutes, constant temperature at $200^{\circ} \mathrm{C}$; followed by a cool down period. Afterwards the mixture was 10-fold diluted before ICP-MS analysis. Sample preparation of the plasma and peritoneal fluid samples involved a simple 1000fold dilution in $0.5 \%$ nitric acid. The ICP-MS system consisted of a Perkin Elmer NexION 350S system equipped with the Syngistix software version 1.1. and an ESI Prep-Fast delivery system controlled by the ESI SC software version 2.9.0.202. The analytes, isotopes of $\mathrm{Pt}$ and the internal standard terbium $(\mathrm{Tb})$ were monitored at $\mathrm{m} / \mathrm{z}$ Pt 194, Pt 195 and Tb 159. Pt concentration in the tumor nodules was expressed as $\mathrm{ng} / \mathrm{mg}$ wet tissue. $\mathrm{Pt}$ concentration in plasma and peritoneal fluid samples was expressed as $\mu \mathrm{g} / \mathrm{mL}$.

\section{Immunohistochemistry for activated caspase-3}

Apoptosis in the center and outer layer of each tumor nodule (sampled from the greater omentum) was evaluated by means of IHC staining for activated caspase-3. Ten $\mu \mathrm{m}$ frozen sections were stored at $-80^{\circ} \mathrm{C}$ until day of analysis. Sections were washed for 5 minutes with aqua destillata followed by cell permeabilization for 5 minutes using PBS-0.03\% Triton X-100 (Fluka, Sigma-Aldrich Chemie, Steinheim, Germany). Nonspecific interactions were minimized through blocking by incubation in $0.3 \%$ hydrogen peroxide (SigmaAldrich Chemie, Steinheim, Germany) in methanol (VWR Chemicals, Fontenay-sous-Bois, France) for 20 minutes, and subsequently incubated with $20 \%$ pre-immune goat serum for 45 minutes. Thereafter, sections were incubated overnight with the primary antibody rabbit active caspase-3 (1/20 dilution, 3015100, Gentaur, Kampenhout, Belgium). Next, sections were incubated with the secondary antibody, goat antirabbit biotin (E043201-8, Agilent Technologies, Diegem, Belgium) for 45 minutes followed by a 30-minute incubation with Streptavidin-HRP (1/100 dilution, Dako, Glostrup, Denmark) and 8 minutes incubation with the TSA $^{\text {TM }}$ Cyanine 3 kit (NEL704A001KT, Perkin-Elmer, Nossegem, Belgium). Cell nucleus was stained by means of DAPI staining (1/1000 dilution in PBS) for 10 minutes. Every step was interspersed with 3 times 5-minute wash steps in PBS. For negative controls, the primary antibody was omitted. Microscopy was performed using a ELYRA PS.1 epi-fluorescence microscope (Carl Zeiss, Jena, Germany). Wide-field images of whole tumor cross sections were obtained by means of tile scans using a Plan-Apochromat 20x/NA0.8 Ph2 objective. DAPI and
Cy3 were sequentially excited with lasers at $405 \mathrm{~nm}$ and $561 \mathrm{~nm}$ respectively. The emission light of DAPI was collected at $420-480 \mathrm{~nm}$ and the Cy3 emission light was collected at $570-620 \mathrm{~nm}$. The acquired image resolution for each tile was $1280 \times 1280$ pixels $^{2}$ at a pixel size of $203 \mathrm{~nm}$. For regions with very high cell density, additional images were acquired with structured illumination microscopy using a Plan-Apochromat 63x/ NA1.40 Oil DIC (Carl Zeiss, Jena, Germany) objective utilizing the same optical filters as described above, resulting in images with $1280 \times 1280$ pixels $^{2}$ at a pixel size of $64 \mathrm{~nm}$. For each structured illumination image, $25 \mathrm{raw}$ images (combination of 5 angles and 5 translations of the diffraction grating) were recorded and subsequently reconstructed into a final high resolution image using automatic 2D processing in ZEN software (version 2011, Carl Zeiss, Jena, Germany). Cells positive for activated caspase- 3 were counted manually in two sections for each tumor nodule (center and outer layer) and expressed as number of cells $/ \mathrm{mm}^{2}$.

\section{Statistical analysis}

Statistical analysis was performed using the SPSS $^{\circledR}$ version 25.0 (IBM Corp., Armonk, NY, USA). The primary objective of this preclinical study was a difference in PA. Sample size was calculated using the statistical program $\mathrm{G}^{*}$ power version 3.0.10 (HeinrichHeine-Universität Dusseldorf). A pilot study was conducted; rats were treated with CRS and oxaliplatinbased HIPEC, BSA-based $(n=5)$ or concentration-based $(n=5)$. The PA was calculated for each of these rats. As these data were normally distributed, sample size was calculated by means of a t-test using a power of 0.90 , alpha of 0.05 and a calculated effect size of 1.04. Equal distribution was tested with the Shapiro-Wilk test. Depending on normality, Student's t-tests or MannWhitney U tests were used to compare continuous data between two treatment groups. One-way ANOVA with post hoc Tukey or Bonferroni and Kruskal-Wallis test were used for continuous data between three groups. The Wilcoxon singed-rank test was used to compare two related samples within each treatment group. Spearman's rank correlation was used to test for possible correlations. Survival analysis was performed using Kaplan-Meier curves and compared by means of log-rank test. Cox survival regression analysis was used to correct for confounding factors. A $p$ value $<0.05$ was considered statistically significant.

\section{Abbreviations}

AUC, area-under-the-curve; BSA, body surface area; c.i., confidence interval; CRS, cytoreductive surgery; HIPEC, hyperthermic intraperitoneal perioperative chemotherapy; ICP-MS, inductively coupled plasma 
mass spectrometry; IHC, immunohistochemistry; IP, intraperitoneal; MTD, maximum tolerated dose; MTT, 3-[4,5-dimethylthiazol-2-yl]-2,5-diphenyltetrazolium bromide; PA, pharmacologic advantage; PCI, peritoneal cancer index; PSM, peritoneal surface malignancy; Pt, platinum; $\mathrm{Tb}$, terbium.

\section{Author contributions}

Lieselotte Lemoine was responsible for the preclinical study design and execution, data management, data analysis, data interpretation, and manuscript writing. Elsy Thijssen and Robert Carleer were responsible for the ICP-MS experiments, interpretation and analysis of the ICP-MS data. Jirka Cops was responsible for the animal management and critically revised the manuscript. Veerle Lemmens was responsible for the fluorescence imaging experiments. Peter Van Eyken was responsible for the pathology part concerning the IHC staining. Paul Sugarbaker and Kurt Van der Speeten were responsible for the study design, interpretation of the results, manuscript revision and editing. All the authors read and approved the final manuscript.

\section{ACKNOWLEDGMENTS}

The authors would like to thank Petra Bex (UHasselt) for her assistance with laboratory and animal experiments. Katrien Wauterickx (UHasselt), Ester Vanmol (Ziekenhuis Oost-Limburg), Anneleen Swennen (Ziekenhuis Oost-Limburg) and Annick Moors (Ziekenhuis Oost-Limburg) for their help with the IHC staining. Dr. Nick Smisdom (UHasselt, Biophysics group) and Prof. dr. Jelle Hendrix (UHasselt, Dynamic Bioimaging Lab) for their help with the fluorescence imaging experiments.

\section{CONFLICTS OF INTEREST}

The authors have no conflict of interest to disclose.

\section{FUNDING}

This work was supported by the Agency for Innovation by Science and Technology (IWT) in Brussels, Belgium (grant number 141631) and Limburgs Kankerfonds. Lieselotte Lemoine and Kurt Van der Speeten are researchers for the Limburg Clinical Research Program (LCRP) supported by the foundation Limburg Sterk Merk (LSM), Hasselt University, Ziekenhuis Oost-Limburg and Jessa Hospital, Belgium. The FWO-Hercules foundation of Flanders (grant number $\mathrm{R}-7087$ ) and the province of Limburg (Belgium) (tUL Impuls II) are acknowledged for funding the microscopy hardware.

\section{REFERENCES}

1. Bushati M, Rovers KP, Sommariva A, Sugarbaker PH, Morris DL, Yonemura Y, Quadros CA, Somashekhar SP, Ceelen W, Dube P, Li Y, Verwaal VJ, Glehen O, et al. The current practice of cytoreductive surgery and HIPEC for colorectal peritoneal metastases: Results of a worldwide web-based survey of the Peritoneal Surface Oncology Group International (PSOGI). Eur J Surg Oncol. 2018; 44:1942-1948. https://doi.org/10.1016/j.ejso.2018.07.003.

2. Verwaal VJ, van Ruth S, de Bree E, van Sloothen GW, van Tinteren H, Boot H, Zoetmulder FA. Randomized trial of cytoreduction and hyperthermic intraperitoneal chemotherapy versus systemic chemotherapy and palliative surgery in patients with peritoneal carcinomatosis of colorectal cancer. J Clin Oncol. 2003; 21:3737-43. https:// doi.org/10.1200/jco.2003.04.187.

3. Quenet F, Elias D, Roca L, Goere D, Ghouti L, Pocard M, Facy O, Arvieux C, Lorimier G, Pezet D, Marchal F, Loi V, Meeus P, et al. A UNICANCER phase III trial of hyperthermic intra-peritoneal chemotherapy (HIPEC) for colorectal peritoneal carcinomatosis (PC): PRODIGE 7. Journal of Clinical Oncology. 2018 (Suppl 18); 36:LBA3503-LBA3503. https://doi.org/10.1200/ JCO.2018.36.18_suppl.LBA3503.

4. Sugarbaker PH. (2013). An overview of peritonectomy, visceral resections, and perioperative chemotherapy for peritoneal surface malignancy. In: Sugarbaker $\mathrm{PH}$, ed. Cytoreductive surgery \& perioperative chemotherapy for peritoneal surface malignancy: textbook and video atlas: Ciné-Med Publishing, Inc.), pp. 1-30.

5. Sugarbaker PH. Peritonectomy procedures. Ann Surg. 1995; 221:29-42.

6. Lemoine L, Sugarbaker P, Van der Speeten K. Drugs, doses, and durations of intraperitoneal chemotherapy: standardising HIPEC and EPIC for colorectal, appendiceal, gastric, ovarian peritoneal surface malignancies and peritoneal mesothelioma. Int $\mathrm{J}$ Hyperthermia. 2017; 33:582-92. https://doi.org/10.1080 /02656736.2017.1291999.

7. Dedrick RL, Myers CE, Bungay PM, DeVita VT Jr. Pharmacokinetic rationale for peritoneal drug administration in the treatment of ovarian cancer. Cancer Treat Rep. 1978; 62:1-11.

8. Flessner MF. The transport barrier in intraperitoneal therapy. Am J Physiol Renal Physiol. 2005; 288:F433-42. https://doi.org/10.1152/ajprenal.00313.2004.

9. Rubin J, Clawson M, Planch A, Jones Q. Measurements of peritoneal surface area in man and rat. Am J Med Sci. 1988; 295:453-8.

10. Albanese AM, Albanese EF, Mino JH, Gomez E, Gomez M, Zandomeni M, Merlo AB. Peritoneal surface area: measurements of 40 structures covered by peritoneum: correlation between total peritoneal surface area and the 
surface calculated by formulas. Surg Radiol Anat. 2009; 31:369-77. https://doi.org/10.1007/s00276-008-0456-9.

11. Ates K, Erturk S, Nergisoglu G, Karatan O, Duman N, Erbay B, Ertug AE. Sex-dependent variations in peritoneal membrane transport properties in CAPD patients. Nephrol Dial Transplant. 1996; 11:2375-6.

12. Mas-Fuster MI, Ramon-Lopez A, Nalda-Molina R. Importance of standardizing the dose in hyperthermic intraperitoneal chemotherapy (HIPEC): a pharmacodynamic point of view. Cancer Chemother Pharmacol. 2013; 72:2734. https://doi.org/10.1007/s00280-013-2204-z.

13. Gremonprez F, Willaert W, Ceelen W. Intraperitoneal chemotherapy (IPC) for peritoneal carcinomatosis: review of animal models. J Surg Oncol. 2014; 109:110-6. https:// doi.org/10.1002/jso.23464.

14. Pelz JO, Doerfer J, Hohenberger W, Meyer T. A new survival model for hyperthermic intraperitoneal chemotherapy (HIPEC) in tumor-bearing rats in the treatment of peritoneal carcinomatosis. BMC Cancer. 2005; 5:56. https://doi.org/10.1186/1471-2407-5-56.

15. Klaver YL, Hendriks T, Lomme RM, Rutten HJ, Bleichrodt RP, de Hingh IH. Intraoperative hyperthermic intraperitoneal chemotherapy after cytoreductive surgery for peritoneal carcinomatosis in an experimental model. $\mathrm{Br}$ J Surg. 2010; 97:1874-80. https://doi.org/10.1002/bjs.7249.

16. Klaver YL, Hendriks T, Lomme RM, Rutten HJ, Bleichrodt RP, de Hingh IH. Intraoperative versus early postoperative intraperitoneal chemotherapy after cytoreduction for colorectal peritoneal carcinomatosis: an experimental study. Ann Surg Oncol. 2012; 19:S475-82. https://doi.org/10.1245/ s10434-011-1984-9.

17. Pelz JO, Doerfer J, Dimmler A, Hohenberger W, Meyer T. Histological response of peritoneal carcinomatosis after hyperthermic intraperitoneal chemoperfusion (HIPEC) in experimental investigations. BMC Cancer. 2006; 6:162. https://doi.org/10.1186/1471-2407-6-162.

18. Hribaschek A, Meyer F, Ridwelski K, Kuester D, Lippert H. Oxaliplatin for chemotherapeutic treatment and prevention of experimental peritoneal carcinomatosis in rats comparing the intraperitoneal and intravenous application mode. Eur Surg Res. 2010; 44:74-81. https:// doi.org/10.1159/000269932.

19. Los G, Mutsaers PH, Ruevekamp M, McVie JG. The use of oxaliplatin versus cisplatin in intraperitoneal chemotherapy in cancers restricted to the peritoneal cavity in the rat. Cancer Lett. 1990; 51:109-17.

20. Sperling J, Schafer T, Ziemann C, Benz-Weiber A, Kollmar $\mathrm{O}$, Schilling MK, Menger MD. Hepatic arterial infusion of bevacizumab in combination with oxaliplatin reduces tumor growth in a rat model of colorectal liver metastases. Clin Exp Metastasis. 2012; 29:91-9. https://doi.org/10.1007/ s10585-011-9432-6.

21. Sperling J, Schafer T, Benz-Weisser A, Ziemann C, Scheuer C, Kollmar O, Schilling MK, Menger MD. Hepatic arterial infusion but not systemic application of cetuximab in combination with oxaliplatin significantly reduces growth of CC531 colorectal rat liver metastases. Int J Colorectal Dis. 2013; 28:555-62. https://doi.org/10.1007/s00384-012-1617-1.

22. Sperling J, Brandhorst D, Schafer T, Ziemann C, BenzWeisser A, Scheuer C, Kollmar O, Schilling MK, Menger MD. Liver-directed chemotherapy of cetuximab and bevacizumab in combination with oxaliplatin is more effective to inhibit tumor growth of CC531 colorectal rat liver metastases than systemic chemotherapy. Clin Exp Metastasis. 2013; 30:447-55. https://doi.org/10.1007/ s10585-012-9550-9.

23. Aarts F, Hendriks T, Boerman OC, Koppe MJ, Oyen WJ, Bleichrodt RP. A comparison between radioimmunotherapy and hyperthermic intraperitoneal chemotherapy for the treatment of peritoneal carcinomatosis of colonic origin in rats. Ann Surg Oncol. 2007; 14:3274-82. https://doi. org/10.1245/s10434-007-9509-2.

24. Goodman MD, McPartland S, Detelich D, Saif MW. Chemotherapy for intraperitoneal use: a review of hyperthermic intraperitoneal chemotherapy and early postoperative intraperitoneal chemotherapy. J Gastrointest Oncol. 2016; 7:45-57. https://doi.org/10.3978/j. issn.2078-6891.2015.111.

25. Gremonprez F, Descamps B, Izmer A, Vanhove C, Vanhaecke F, De Wever O, Ceelen W. Pretreatment with VEGF(R)-inhibitors reduces interstitial fluid pressure, increases intraperitoneal chemotherapy drug penetration, and impedes tumor growth in a mouse colorectal carcinomatosis model. Oncotarget. 2015; 6:29889-900. https://doi.org/10.18632/oncotarget.5092.

26. Elias D, Bonnay M, Puizillou JM, Antoun S, Demirdjian S, El OA, Pignon JP, Drouard-Troalen L, Ouellet JF, Ducreux M. Heated intra-operative intraperitoneal oxaliplatin after complete resection of peritoneal carcinomatosis: pharmacokinetics and tissue distribution. Ann Oncol. 2002; 13:267-72.

27. Mehta AM, Van den Hoven JM, Rosing H, Hillebrand MJ, Nuijen B, Huitema AD, Beijnen JH, Verwaal VJ. Stability of oxaliplatin in chloride-containing carrier solutions used in hyperthermic intraperitoneal chemotherapy. Int J Pharm. 2015; 479:23-7. https://doi.org/10.1016/j. ijpharm.2014.12.025.

28. Lagast N, Carlier C, Ceelen WP. Pharmacokinetics and Tissue Transport of Intraperitoneal Chemotherapy. Surg Oncol Clin N Am. 2018; 27:477-94. https://doi. org/10.1016/j.soc.2018.02.003.

29. Carlier C, Mathys A, De Jaeghere E, Steuperaert M, De Wever O, Ceelen W. Tumour tissue transport after intraperitoneal anticancer drug delivery. Int J Hyperthermia. 2017; 33:534-42. https://doi.org/10.1080/02656736.2017.1 312563.

30. Klaver YL, Hendriks T, Lomme RM, Rutten HJ, Bleichrodt RP, de Hingh IH. Hyperthermia and intraperitoneal chemotherapy for the treatment of 
peritoneal carcinomatosis: an experimental study. Ann Surg. 2011; 254:125-30. https://doi.org/10.1097/ SLA.0b013e3182197102.

31. Pelz JO, Doerfer J, Decker M, Dimmler A, Hohenberger W, Meyer T. Hyperthermic intraperitoneal chemoperfusion (HIPEC) decrease wound strength of colonic anastomosis in a rat model. Int J Colorectal Dis. 2007; 22:941-7. https:// doi.org/10.1007/s00384-006-0246-y.

32. Sugarbaker PH. Cytoreductive surgery and hyperthermic intraperitoneal chemotherapy in the management of gastrointestinal cancers with peritoneal metastases: Progress toward a new standard of care. Cancer Treat Rev. 2016; 48:42-9. https://doi.org/10.1016/j.ctrv.2016.06.007.

33. Lemoine L, Thijssen E, Noben JP, Adriaensens P, Carleer R, Speeten KV. A validated inductively coupled plasma mass spectrometry (ICP-MS) method for the quantification of total platinum content in plasma, plasma ultrafiltrate, urine and peritoneal fluid. J Pharm Biomed Anal. 2018; 152:3946. https://doi.org/10.1016/j.jpba.2018.01.033. 